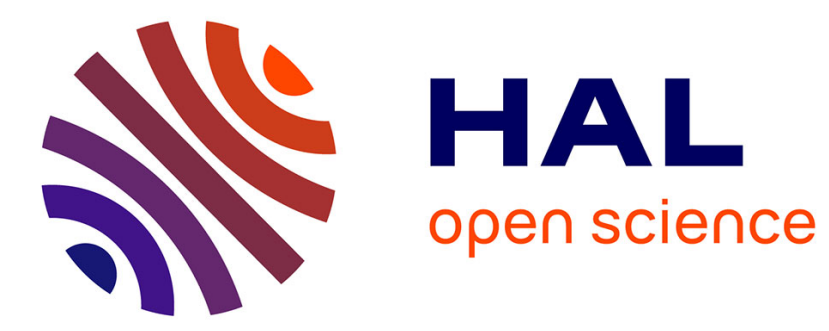

\title{
Dynamical modeling of tissue electroporation
}

Damien Voyer, Aude Silve, Lluis M. Mir, Riccardo Scorretti, Clair Poignard

\section{To cite this version:}

Damien Voyer, Aude Silve, Lluis M. Mir, Riccardo Scorretti, Clair Poignard. Dynamical modeling of tissue electroporation. Bioelectrochemistry, 2018, 119, pp.98 - 110. 10.1016/j.bioelechem.2017.08.007 . hal-01598846

\section{HAL Id: hal-01598846 \\ https://hal.inria.fr/hal-01598846}

Submitted on 5 Oct 2017

HAL is a multi-disciplinary open access archive for the deposit and dissemination of scientific research documents, whether they are published or not. The documents may come from teaching and research institutions in France or abroad, or from public or private research centers.
L'archive ouverte pluridisciplinaire HAL, est destinée au dépôt et à la diffusion de documents scientifiques de niveau recherche, publiés ou non, émanant des établissements d'enseignement et de recherche français ou étrangers, des laboratoires publics ou privés. 


\title{
Dynamical modeling of tissue electroporation
}

\author{
Damien Voyer ${ }^{\mathrm{a}}$, Aude Silve ${ }^{\mathrm{c}}$, Lluis M. Mir ${ }^{\mathrm{d}}$, Riccardo Scorretti ${ }^{\mathrm{b}}$, Clair Poignard ${ }^{\mathrm{e}, 1}$ \\ ${ }^{a}$ EIGSI La Rochelle, F-17041 La Rochelle Cedex, France \\ ${ }^{b}$ Université de Lyon, Ampère, UMR 5005, F-69134 Ecully Cedex, France \\ ${ }^{c}$ Karlsruhe Institue of Technology, Institute of Pulsed Power, F-76344 Eggenstein-Leopoldshafen, Germany \\ ${ }^{d}$ Vectorology and Anticancer Therapies, UMR 8203, CNRS, Univ. Paris-Sud, Gustave Roussy, Université \\ Paris-Saclay, F-94805 Villejuif, France \\ ${ }^{e}$ INRIA de Bordeaux-Sud Ouest, Team MONC, F-33405 Talence Cedex, France
}

\begin{abstract}
In this paper, we propose a new dynamical model of tissue electroporation. The model is based on equivalent circuit approach at the tissue. Considering two current densities from cells and extracellular matrix, we identify the macroscopic homogenised contribution of the cell membranes. Our approach makes it possible to define a macroscopic homogenised electric field and a macroscopic homogenised transmembrane potential. This provides a direct link between the cell scale electroporation models and the tissue models. Finite element method adapted to the new non linear model of tissue electroporation is used to compare experiments with simulations. Adapting the phenomenological electroporation model of Leguèbe et al. to the tissue scale, we calibrate the tissue model with experimental data. This makes two steps appear in the tissue electroporation process, as for cells. The new insight of the model lies in the well-established equivalent circuit approach to provide a homogenised version of cell scale models. Our approach is tightly linked to numerical homogenisation strategies adapted to bioelectrical tissue modeling.
\end{abstract}

Keywords:

Electroporation, biological tissue, electric field, phenomenological modeling, theory of pores

\section{Introduction}

Electroporation-based therapies (EPT) consist in applying high voltage short pulses to tumor cells (typically several hundred volts per centimeter during about one hundred microseconds) in order to create defects in the cell membrane. They provide interesting alternatives to standard non surgical ablative techniques, for instance for deep seated tumors located near vital organs or important vessels. However, even though the rationale of electroporation is quite well quantified at the cell scale, the lack of numerical models of tissue electroporation prevents the systematic use of these therapies in cancer treatments. In particular, the computation of the time-dependent electric field within biological tissues is a

\footnotetext{
${ }^{1}$ clair.poignard@inria.fr
} 
crucial issue that still has to be addressed. This computation is required in order to appropriately choose the electrodes parameters (number, shape and position) and the pulse delivery (amplitude, pulse duration, number of pulses and repetition frequency).

At the cell scale, electroporation consists of the emergence of defects in cell membrane when the transmembrane potential (TMP) is higher than the membrane breakdown voltage. These defects increase the membrane permeability and thus the membrane conductivity. In the past decade, substantial progresses have been made in the modeling of cell scale electroporation. The widespread approach is based on the time evolution of cell membrane pore density derived from Smoluchowski equation. Considering the geometry and the electrical properties of a single cell, partial differential equations have been solved in [1] using the finite difference method to compute the time evolution of the TMP and the pore density at any point of the cell surface. A similar issue has been addressed in [2] using the transport lattice method, which provides an electric circuit representation of the equations. The Smoluchowski-based approach has been extended to study the electrical response of multiple cells and even tissues by Esser et al. [3]. The cell model of Debruin and Krassowska proposed in [1] has been extended in $[4,5]$, where time and spatial evolution of pore radii distribution are included. Recently, phenomenological approaches have been proposed by Leguèbe et al. $[6,7]$ to provide models with less parameters for calibration purposes. Therefore the cell scale modeling is fairly well established and validated with experimental data.

At the tissue scale, the electroporation modeling is still in progress. Indeed, most of the current models are based on nonlinear static descriptions of the electric field. The tissue is generally described as a conductive medium with conductivity $\sigma[8,9,10,11]$. The electric potential $\varphi$ at the tissue scale is given as the solution to the following problem

$$
\nabla \cdot(\sigma \nabla \varphi)=0
$$

with appropriate boundary conditions reflecting the pulse delivery. Electroporation is described as an increase of the medium conductivity, thanks to the use of a sigmoid function $\beta$ depending on the electric field amplitude:

$$
\sigma=\beta(\nabla \varphi)
$$

The function $\beta$ is a regularized step function between $\sigma_{0}$ and $\sigma_{1}$. For instance

$$
\beta(\nabla \varphi)=\frac{2\left(\sigma_{0}-\sigma_{1}\right)}{1+e^{\|\nabla \varphi\|^{2} / E_{e p}^{2}}}+\sigma_{1}
$$

where $\sigma_{0}$ is the medium conductivity before electroporation, $\sigma_{1}$ is the conductivity of the fully electroporated tissue, and $E_{e p}$ is the field amplitude above which electroporation occurs. According to Ivorra et al. [12], the choice of the sigmoid is not very important, but the choice of the threshold is crucial since it drives the increase of the conductivity. Among the large variety of the static models, one can cite the numerous works of D. Miklavčič's group (see $[8,13]$ and reference therein).

In these descriptions, the final conducting state of the tissue is given without accounting for the dynamical effects of the pulses $[14,15]$. In particular the capacitive response of the 
tissue, and the time-evolution of the tissue conductivity are not described. Therefore accurate calibrations of the model parameters with the chronograms of the measured intensities are hardly obtainable [16, 5]. In order to prevent these drawbacks, Langus et al. [17] proposed recently a new discrete-in-time model of tissue electroporation. The model is designed to account for the dynamical behaviour of the tissue conductivity, thanks to phenomenological considerations. Thanks to an accurate calibration procedure, they managed to obtain accurate descriptions of the tissue electroporation. However the model depends highly on the choice of the step time $\Delta t$ (see page 4 of [17]), and there is no evident links with the time continuous equations arising from classical physics. Moreover the links between the cell scale model and the tissue scale model are not clear.

The aim of the paper is to present a new dynamical continuous model, which describes accurately the time evolution of the tissue conductivity. The new feature of the modeling consists in proposing a link between the cell scale models and our tissue model thanks to an appropriate definition of the homogenized TMP, which somehow corresponds to the standard transmembrane potential at the macroscopic tissue scale. Our modeling approach is tightly linked to the numerical homogenisation approach using bidomain equation [18], providing a pathway between the cell and the tissue scales.

In section 2, we present our new dynamical electric model of tissue. Let us present the heuristics of our modeling, which is detailed in the ad hoc section. The model is based on the description of two current densities, similarly to Langus et al. (see equation 3 page 3, [17]). The current $\mathbf{J}_{\text {cell }}$ flows through the cells and the conductive current $\mathbf{J}_{e}$ flows through the extracellular medium. While Langus et al. propose a time-step dependent equation on $\mathbf{J}_{\text {cell }}$, which is hardly linked with classical differential equations (equation 9 page 4 [17]), we propose here an equivalent electric circuit approach. The vector field $\mathbf{J}_{\text {cell }}$ satisfies thus an ordinary differential equation, whose source term depends on the macroscopic electric field $-\nabla \varphi$. From these two vector current densities, we define the homogenised membrane electric field $\mathbf{E}_{m}$, from which we define the amplitude $v_{m}$ of the homogenised transmembrane voltage. These definitions make it possible to link our tissue model with cell scale electroporation models. Based on the cell scale modeling of Leguèbe et al. [7], we then propose our new model of tissue electroporation. Similarly to [7], the increase of the tissue conductivity is described thanks to two variables, $X_{1}$ and $X_{2}$, with different characteristics times. In section 3 , the model is validated thanks to the comparison with the experimental measurements of Sel et al. [8]. In vivo experiments were carried out in [8] using one pulse of $100 \mu \mathrm{s}$ on rabbit livers with different electrode diameters and different voltages. The chronograms of the total current that flows through the needles are accurately described by our model. A second comparison is proposed in section 3 with simulation results obtained in [3] concerning the spatial distribution of the electric field in a similar tissue system.

According to [7], the variable $X_{1}$ is somehow related to the creation of pores, while $X_{2}$ describes the changes of states of the lipids affected by the electric field. In section 4 , we propose another interpretation of these variables in terms of pore density and pore growth, in order to provide a link between Leguèbe et al. approach and the approach of Weaver's group. 
Remark 1.1 (Omitting the electrolysis). The synergistic combination of electrolysis and electroporation seems promising in cancer treatments as reported by Maglietti, Stehling et al. [19, 20] and references therein. The equations of the electrolysis are based on PoissonNernst-Planck system of equations, which link the flux of the ion concentrations to the electric potential. In tissue, which is a highly heterogeneous medium with cell membrane as barriers, such equations are not so clearly established. In particular, the ionic diffusion, that holds in a homogeneous solute medium does not hold any more. It is well-known in mathematical sciences that in tissues, due to the cell membranes, bidomain equation should be preferred to the standard diffusion one [21, 22]. However the situation in electroporation is still unclear and the complete model would involve too many parameters that would make it unfittable with the data. For the sake of simplificity, we omit this very challenging aspect of electroporation. We are confident that modeling the electrolysis phenomenon would improve the model, without changing dramatically the results presented in this paper.

\section{New electric model in transient regime at tissue scale}

\subsection{Electric circuit at the tissue scale}

The electric model at the tissue scale is based on the equivalent circuit shown in Schematic 1, which is similar to the model proposed in [23] from bioimpedancemetry measurements. According to the organization of tissues proposed by Dissado et al. [24], the cells are tightly packed, and these cell blocks are electrically connected together by blood vessels, ducts and extracellular matrix. The conductive extracellular medium is thus represented by the resistance $R_{e}$, whereas the branch $R_{c}+R_{m} / / C_{m}$ accounts for the cells influence. The resistance $R_{c}$ globally accounts for the conductive intracellular medium. The cell membrane effects are represented by a capacitance $C_{m}$ in parallel with a resistance $R_{m}$. The capacitance accounts for the polarization of the lipid bilayer. The resistance $R_{m}$ represents the leaking of the membrane, which becomes significant when electroporation occurs. The voltage $u_{m}$ is related to the TMP 2 and it has to be intended as the homogenised TMP at the tissue scale when the size of the tissue sample is reduced to the size of the cell. This assumption is supported by the analogy that can be made between our model at the tissue scale and the existing cell scale models as explained in Appendix A.

\section{Here Schematic 1.}

Applying the standard circuit laws to Schematic 1 leads to the following equalities:

$$
i=i_{\text {cell }}+i_{e}, \quad i_{\text {cell }}=2\left(C_{m} \frac{d u_{m}}{d t}+u_{m} / R_{m}\right)=\left(v-2 u_{m}\right) / R_{c}, \quad i_{e}=v / R_{e},
$$

\footnotetext{
${ }^{2}$ Note that voltage across the circuit element $R_{m} / / C_{m}$ is $2 u_{m}$ because of the assumed symmetry of a cell: current enters the cells through one hemisphere and comes out through the other one so that the membrane is crossed twice.
} 
from which we infer the differential equation satisfied by the intensity $i_{\text {cell }}$ in terms of $i_{e}$ (see Appendix B for more details):

$$
\left(\frac{1}{R_{c}}+\frac{1}{R_{m}}\right) i_{c e l l}+C_{m} \frac{d i_{c e l l}}{d t}=\frac{R_{e}}{R_{c}}\left(\frac{i_{e}}{R_{m}}+C_{m} \frac{d i_{e}}{d t}\right) .
$$

Neglecting the time-evolution of the extracellular intensity $i_{e}$, we then obtain

$$
\left(\frac{1}{R_{c}}+\frac{1}{R_{m}}\right) i_{c e l l}+C_{m} \frac{d i_{c e l l}}{d t}=\frac{R_{e}}{R_{c} R_{m}} i_{e} .
$$

This equation is used to derive our model. More precisely, we consider two current densities, $\mathbf{J}_{e}$ and $\mathbf{J}_{\text {cell }}$, which respectively come from the extracellular medium and the cell compartments. Denote by $\sigma_{e}, \sigma_{c}$ and $\sigma_{m}$ the homogenised conductivity tensors of the extracellular medium, the cell cytoplasms and the membranes respectively. Then the above equation (2) links $\mathbf{J}_{\text {cell }}$ to $\mathbf{J}_{e}$ as

$$
\left(\sigma_{c}+\sigma_{m}\right) \mathbf{J}_{\text {cell }}+C_{m} \frac{d \mathbf{J}_{c e l l}}{d t}=\sigma_{c} \sigma_{m} \sigma_{e}^{-1} \mathbf{J}_{e}
$$

Remark 2.1 (On the simplicity of the equivalent circuit approach). The equivalent circuit given in Schematic 1 reproduces the frequency response of the cells in the frequency range related to a $\beta$-dispersion as reported by Miklavčič et al.[25]. It corresponds to the frequency bandwidth investigated when milliseconds or microseconds pulses are delivered. However, biological tissues are complex systems and effective medium theory should theoretically be applied in order to provide more realistic descriptions [26]. However this would increase the complexity of the model. For example, the mixture formula proposed by Bruggeman-Hanai to model the Maxwell-Wagner relaxation with high cell concentration leads to a system response characterized by a distribution of relaxation times [27]. An alternative method to predict more accurately the response of the biological tissue consists in using a Cole-Cole model [26]. A constant phase element should then be introduced in the electric circuit in order to obtain a more realistic frequency response [23].

However all these theoretical approaches would provide much more complex models, with unmeasurable parameters. Our goal is to provide a model as simple as possible in order to fit the parameters with the experiments. The constant phase element is reduced to the capacitance $C_{m}$. This choice avoids the estimation of a parameter, without modifying dramatically the response of the system. As shown hereafter, more attention must be paid to the modeling of the electroporation process.

2.2. Physical and constitutive laws and homogenised membrane electric field at the tissue scale

Following the circuit approach of Schematic 1, we propose here a phenomenological electric model of tissue. We consider two cell current densities: $\mathbf{J}_{\text {cell }}$ accounts for the cell electric 
current density and $\mathbf{J}_{e}$ is the extracellular current density. According to the charge conservation law, these current densities satisfy

$$
\nabla \cdot\left(\mathbf{J}_{e}+\mathbf{J}_{\text {cell }}\right)=0, \quad \text { in the tissue. }
$$

Since the extracellular medium is a conductive medium, the extracellular current density is given in terms of the macroscopic electric field $-\nabla \varphi$ :

$$
\mathbf{J}_{e}=\sigma_{e} \nabla \varphi
$$

where $\sigma_{e}$ is the equivalent homogenised conductivity tensor of the extracellular medium. Denote by $\sigma_{c}$ the equivalent homogenised conductivity tensor of the cell cytoplasm. The circuit approach given by (3) combined to the constitutive law (7) leads to the differential equation satisfied by $\mathbf{J}_{c}$

$$
\left(\sigma_{c}+\sigma_{m}\right) \mathbf{J}_{c e l l}+\epsilon_{m} \frac{d \mathbf{J}_{c e l l}}{d t}=\sigma_{c} \sigma_{m} \nabla \varphi
$$

where $\epsilon_{m}$ is the equivalent homogenised permittivity of the membranes and $\sigma_{m}$ is the equivalent homogenised conductivity tensor of the membrane.

As in the cell scale model, we assume that $\sigma_{m}$ only is affected by the homogenised electric field around the membrane. The other electrical properties do not change during pulse delivery. One can define the homogenised membrane electric field $\mathbf{E}_{m}$ by

$$
\mathbf{E}_{m}=\frac{1}{2}\left(\nabla \varphi-\sigma_{c}^{-1} \mathbf{J}_{c e l l}\right), \quad \text { in the tissue. }
$$

According to Schematic 1, this definition is analogous to the relationship $u_{m}=\frac{1}{2}\left(v-R_{c} i_{c e l l}\right)$ - see appendix $\mathrm{B}$ for the complete derivation of this equation. This homogenised membrane electric field is the keypoint of the modeling, since it will make it possible to define the amplitude of the homogenised TMP. This will provide the link between the cell scale models and our tissue electroporation model. Let us emphasize that the electrochemical reactions which may happen close to electrodes are not taken into account. In forthcoming works we plan to include such reactions as well as the increase of $\mathrm{pH}$ during the pulses as proposed by Magliettiet al. [19], but these considerations are far from the scope of the present paper.

\subsection{Phenomenological law on $\sigma_{m}$ to account for the electroporation process}

Many different models of cell electroporation have been proposed in the literature $[28,1$, 29, 16, 2, 4, 5]. One can cite for instance the model of Krassowska et al. [4], which is based on the description of the pore density and the growth of the pores. Among the different models, we choose here the model of Leguèbe et al. [7]. This phenomenological model has been designed for calibration purpose: it involves as few parameters as possible, and account for all the behaviours reported by the experiments. However another choice of cell scale model could have been made without changing the spirits of the modeling. It is worth noting that at the cell scale, the amplitude of the TMP drives the electroporation process $[4,6,7]$. It 
is thus important to define the amplitude of the homogenised TMP, $v_{m}$, at the tissue scale. Consider a sample of tissue reduced to the mean diameter of the cells $d_{c}: v$ in Schematic 1 is then related to the voltage seen by the whole cell and $u_{m}$ to the voltage across the membrane. Thus $v_{m}$ is defined as

$$
v_{m}(t, x)=d_{c}\left|\mathbf{E}_{m}(t, x)\right|, \quad \text { at any time } t \text {, at any point } x \text { in the tissue. }
$$

Remark 2.2. The quantity $v_{m}$ defined here is not to be intended as the true TMP in a particular point of the cell membrane, but rather as an equivalent quantity which accounts for the mean effect on cells in the tissue. See appendix B for more details. by

Following Leguèbe et al. [7], we thus define the homogenised membrane conductivity $\sigma_{m}$

$$
\sigma_{m}\left(t, v_{m}\right)=\sigma_{m 0}+\sigma_{m 1} X_{1}\left(t, v_{m}\right)+\sigma_{m 2} X_{2}\left(t, X_{1}\right),
$$

where $\sigma_{m 0}$ is the conductivity for an intact membrane, $\sigma_{m 1}$ and $\sigma_{m 2}$ are respectively the membrane conductivities of poration and long-term permeabilization (see [7]). The functions $X_{1}$ and $X_{2}$ are the respective degree of poration and permeabilization that vary between 0 and 1 . They are ruled by two different time differential equations.

The first process $X_{1}$ describes the quick and high conductivity increase of the cell membranes. It satisfies the following equation

$$
\frac{d X_{1}}{d t}= \begin{cases}\frac{\beta_{1}\left(v_{m}\right)-X_{1}}{\tau_{1}} & \text { if } \beta_{1}\left(v_{m}\right) \geq X_{1}, \\ 0 & \text { else, }\end{cases}
$$

where $\tau_{1}$ is the characteristic time of the increase of $X_{1}$. The function $\beta_{1}$ is any sigmoid function, the parameters of which have to be fitted from experiments. In this paper we choose

$$
\beta_{1}\left(v_{m}\right)=1 / 2\left(1+\tanh \left(k_{1}\left(v_{m}^{2} / V_{t h}^{2}-1\right)\right)\right),
$$

where $V_{t h}$ is the threshold for the amplitude of the homogenised TMP over which the first process begins, and $k_{1}$ a coefficient to modulate the effect of the threshold.

The second process $X_{2}$ is somehow related to the change of the membrane lipids. It depends on both $X_{1}$ and macroscopic electric field but for a sake of simplicity, the second dynamic is assumed to depend ${ }^{3}$ exclusively on $X_{1}$. We set

$$
\frac{d X_{2}}{d t}= \begin{cases}\frac{\beta_{2}\left(X_{1}\right)-X_{2}}{\tau_{2}} & \text { if } \beta_{2}\left(X_{1}\right) \geq X_{2} \\ 0 & \text { else }\end{cases}
$$

where $\tau_{2}$ is a characteristic time for the increase of $X_{2}$. We assume that the time to replace the changes of the lipids is much longer than the pulse delivery, and thus there is no decrease of $X_{2}$. This is justified since exocytosis lasts several minutes while the pulse duration is below $1 \mathrm{~ms}$. Here again, $\beta_{2}$ is the 2-parameter sigmoid function defined by

$$
\beta_{2}\left(X_{1}\right)=1 / 2\left(1+\tanh \left(k_{2}\left(X_{1} / X_{t h}-1\right)\right)\right) .
$$

\footnotetext{
${ }^{3}$ This assumption is justified by the fact that $X_{1}$ increases only for large transmembrane voltage
} 
Remark 2.3 (On the choice of the electroporation model). There are several papers in the literature where $100 \mu s$ voltage pulses have been applied between two needles inserted into a biological tissue in order to induce electroporation (see for example [8, 30]). Chronograms of the current flowing through the needles always present the same shape: after a partial charge of the membrane, there is a first dynamic in the electroporation process that ends around $1 \mu \mathrm{s}$ when the current reaches a minimum value. Then, there is a second dynamic during which the current slowly increases and that lasts until the voltage is turned off. When no electroporation occurs, current reaches a minimum value after a few microseconds when the charge of the membrane is complete. However, the first dynamic of the electroporation process can be clearly identified in the first microseconds when the voltage is high enough. This has been proven in [31] thanks to an analysis of the minimum value of the current for different voltages. It can also be shown by the study of instantaneous conductance measured between the needles in [30]. Without the first dynamic, the value of instantaneous conductance would be the same for all the voltages during the charge of the membrane. Conversely, results reported in the second figure of [30] show that instantaneous conductance changes strongly with the voltage, meaning that a nonlinear process is already operating during the first microseconds in addition to the membrane charge.

\section{Comparison between experimental and numerical results}

\subsection{Experimental set-up}

To evaluate accuracy of the phenomenological model, simulations have been carried out in relation with the experiments reported in [8] that were performed in vivo on rabbit livers: single pulses of $100 \mu$ s with different amplitudes were delivered using needles inserted perpendicularly to the tissue surface. The geometry of the needles is shown in the first figure of [8]: the length of the needles was $7 \mathrm{~mm}$ and the inner distance between them was $8 \mathrm{~mm}$. Experiments were performed on three rabbits using three different diameters $\varnothing=0.3,0.7$ and $1.1 \mathrm{~mm}$ for the needles. The current flowing through the needles was recorded for different voltage ranging from $200 \mathrm{~V}$ to $1100 \mathrm{~V}$. Although the shape of the needles induces a non uniform distribution of the electric field, a nominal electric field is introduced for convenience: it is defined as the ratio of the voltage to the electrode distance. Since the term "nominal electric field" might be confusing, it is referred to as "V/d-ratio EF" throughout the paper.

The V/d-ratio EF applied in the experiments of [8] ranged from $250 \mathrm{~V} / \mathrm{cm}$ to $1375 \mathrm{~V} / \mathrm{cm}$.

\subsection{Numerical simulations}

The length of the needles used in [8] is large compared with the diameter of the needles thus the peak effects are negligible and the solution should be invariant along the needles axis. Preliminary non provided simulations have confirmed this behaviour. Therefore, for numerical purpose we consider the $2 \mathrm{D}$ configuration. To compare the data with the simulations, the numerical intensities are then multiplied by the length of the electrodes i.e. by $7 \mathrm{~mm}$. 
The tissue is a square of size $32 \mathrm{~mm} \times 32 \mathrm{~mm}$. Neumann homogeneous boundary conditions are imposed on the outer boundary of this domain. The two needles are located in the middle of the domain, and the potential $\varphi$ is forced on the boundary of the electrodes. Thanks to the symmetries, the computational domain can be reduced to a quarter of the initial geometry with appropriate boundary conditions set on the symmetric planes (see Schematic 2).

\section{Here Schematic 2.}

To solve equation (4), the discretization of $\varphi$ in the spatial domain is made using the finite element method, with $P_{2}$-elements for consistency purposes (see the mesh shown Figure 2). The discretization in time is performed using the standard semi-implicit Euler scheme to solve equations (6), (10) and (12). At each time step, the non linear system is solved thanks to a fixed point method similar to Kelley [32]. The mesh is generated by the $\mathrm{C}^{++}$library Gmsh and we use the library GetFem to implement the finite element method [33].

\subsection{Choice of the parameters}

Table 1 reports the parameters set to fit with the experimental data.

\section{Here Table 1.}

The relative permittivity $\epsilon_{m}$ of the cell membranes at the tissue scale ranges between 40000 and 60000 , which is consistent with the large value of the rabbit's liver permittivity measured experimentally in the range of frequencies related to the $\beta$-dispersion as reported in [34]. These values are several order of magnitude higher that the cell scale values due to the relative volume occupied by the membrane in the tissue arrangement. Some parameters of Table 1 can be related to the static model proposed in [8].

- The minimum value of the tissue conductivity in the static problem (see [8]) is reached when the electric field is much smaller than the electric field threshold. The value given in [8] is $0.067 \mathrm{~S} / \mathrm{m}$ but the authors in [8] mention that this last value is smaller than the mean value reported for livers in the literature. To fit with the experiments we impose the extracellular conductivity $\sigma_{e}$ between 0.08 and $0.12 \mathrm{~S} / \mathrm{m}$, which is in the same range of tissue conductivities in the literature.

- The maximum value of the conductivity in the static problem [8] is reached when the electric field is much higher than the electric field threshold. The value given in $[8]$ is $0.241 \mathrm{~S} / \mathrm{m}$ and it should be equal to $\left(\sigma_{e}+\sigma_{c}\right)$. Table 1 reports a value for $\left(\sigma_{e}+\sigma_{c}\right)$ between 0.32 and $0.43 \mathrm{~S} / \mathrm{m}$. Once again, the values used in our model are larger than those used in [8] but in the same proportion as for $\sigma_{e}$.

- We set the characteristic diameter of the cell to $22 \mu \mathrm{m}$, which is the value for hepatocytes given in [8]. 
- The critical transmembrane voltage over which electroporation appears has been calculated in [8] from Schwan's equation. The computed value is $0.50 \mathrm{~V}$ and this result is close to the value of $V_{t h}=0.52 \mathrm{~V}$ used in our model.

- The quantity $\epsilon_{m} \epsilon_{0} / \sigma_{c}$ is the characteristic time for charging the membrane when the tissue is submitted to a step excitation. The relaxation frequency related to the $\beta$ dispersion for a rat's liver has been estimated to $f_{c}=0.072 \mathrm{MHz}$ in [34], leading to a characteristic time $\tau_{c}=1 /\left(2 \pi f_{c}\right)=2.21 \mu \mathrm{s}$. In order to fit with the experimental chronograms, the value of $\epsilon_{m}$ in our model has been adjusted so that $\epsilon_{m} \epsilon_{0} / \sigma_{c}=1.52 \mu \mathrm{s}$ for the three sizes of the needles: this value is in the same range of values as the one found for $\tau_{c}$ in [34].

The sigmoid function $\beta_{1}$ (resp. $\beta_{2}$ ) involves the dimensionless stiffness parameter $k_{1}$ (resp. $k_{2}$ ) and the threshold $v_{t h}$ (resp. $X_{t h}$ ). The values of these parameters chosen to fit the data are given at Table 1. Similarly to Leguèbe et al. [7], the stiffness parameter $k_{1}$ is set to 40. It is much higher than $k_{2}$ (set to 10), meaning that the transition from the nonelectroporated state to the electroporated state is sharper than the increase of $X_{2}$, as shown in [7].

\section{Here Figure 1.}

\subsection{Simulation results}

\subsubsection{Comparison with the experiments}

The numerical intensities are computed as the integral along the electrodes of the normal component of the electric field multipled by the length of the needle, namely

$$
I_{\text {electrode }}=\ell_{\text {needle }} \int_{\text {electrode }} \nabla \varphi \cdot \mathbf{n} \mathbf{d s}
$$

where $\ell_{\text {needle }}$ is the length of the needle, which is $7 \mathrm{~mm}$ in [8]. Let us mention that the 2D configuration makes it possible to describe precisely the electrodes with the fine mesh presented in Schematic 2 . Therefore the above integral $I_{\text {electrode }}$ is precisely computed. For 3D-simulations, a similar mesh would increase dramatically the computational cost of the simulations, and thus the calibration procedure.

Figure 2 shows the chronograms of the measured and computed electric currents flowing through the needles when a $100 \mu$ s-long pulse is applied between the needles, with different $\mathrm{V} / \mathrm{d}-$ ratios EF and for the three sizes of the needles. Note that the $\mathrm{V} / \mathrm{d}-$-ratios EF are higher in the case $\varnothing=0.7 \mathrm{~mm}$ compared to the cases $\varnothing=0.3 \mathrm{~mm}$ and $\varnothing=1.1 \mathrm{~mm}$. This explains why the maximum current is achieved in the experiments performed with $\varnothing=0.7 \mathrm{~mm}$.

\section{Here Figure 2.}

In the case $\varnothing=0.3 \mathrm{~mm}$, there is a good agreement between the simulations and the experiments, as shown in Figure 2 (a). Concerning the case $\varnothing=0.7 \mathrm{~mm}$, we have changed a little bit the value of $\sigma_{m 2}$ compared with the previous case in order to obtain a better fit 
of the second dynamic. However a discrepancy is observed between the simulations and the measurements with the $\mathrm{V} / \mathrm{d}$-ratio $\mathrm{EF}$ of $1125 \mathrm{~V} / \mathrm{cm}$. This discrepancy is mainly due to the first dynamic $X_{1}$, which is underestimated. In the case $\varnothing=1.1 \mathrm{~mm}$, the conductivity of the extracellular medium that has been slightly increased, and the intracellular conductivity that has been slightly decreased. These changes may be due to the variability among the rabbit's liver used in these last experiments. The results show a good agreement between the simulations and the measurements, except for the $\mathrm{V} / \mathrm{d}$-ratio EF of $1000 \mathrm{~V} / \mathrm{cm}$. The deviation holds also for the first dynamic $X_{1}$ which is still underestimate, like in case $\varnothing=0.7 \mathrm{~mm}$. A possible explanation comes from the fact that electrochemical reactions around the electrodes/tissue interfaces are not described by the model. The impact of this phenomenon would change with the size of the needles, since the surface of the electrodes changes with the diameter. However, the overall calibration is quite satisfactory, since our modeling makes it possible to describe the two dynamics of the current as observed by the experiments.

\subsubsection{Interpretation in terms of electroporation dynamics}

The present model brings new insights on electroporation dynamics at the tissue scale, in particular in terms of electroporation dynamics. We focus now on the second set of experiments with $\varnothing=0.7 \mathrm{~mm}$. We choose two different points of the computational domain. The first point $P_{N}$ is chosen on the boundary of one needle, and the second point $P_{M}$ is the middle point between the two electrodes (see Schematic 2). The amplitude of the homogenised TMP at the tissue scale $v_{m}$ has been computed from equation (8). Figure 3 shows the time evolution of $v_{m}$ at the two points $P_{N}$ and $P_{M}$. At the point $P_{N}$, $v_{m}$ largely overcomes the threshold $v_{t h}$ during the first dynamic $(t<1 \mu \mathrm{s})$ and then it decreases regularly during the second dynamic $(t>1 \mu \mathrm{s})$. At $P_{M}, v_{m}$ reaches the threshold $v_{t h}$ during the first dynamic $(t<1,2,3$ or $4 \mu$ s depending on the $\mathrm{V} / \mathrm{d}$-ratio EF) and then it weakly decreases during the second dynamic. These different behaviours are due to the non uniform distribution of the electric field between the needles: the amplitude of the electric field is higher in the vicinity of the needles [8].

\section{Here Figure 3.}

The time evolutions of $X_{1}$ and $X_{2}$ at the points $P_{N}$ and $P_{M}$ are displayed in Figure 4. As expected, $X_{1}$ quickly reaches a stationary regime at both points but the final value is higher at the point $P_{N}$ since the amplitude of the homogenised TMP is much larger during the first microsecond (see Figure 3). At the point $P_{M}$, a delay is observed in the initiation of $X_{1}$ depending on the $\mathrm{V} / \mathrm{d}$-ratio $\mathrm{EF}$ : it corresponds to the amount of time necessary to charge the membrane. For example, $X_{1}$ starts increasing from $4 \mu \mathrm{s}$ in the case $625 \mathrm{~V} / \mathrm{cm}$ and the amplitude of the homogenised TMP at the tissue scale reported in Figure $3 \mathrm{~b}$ reaches $0.46 \mathrm{~V}$ at same time. This last value corresponds to the minimum value from which the function $\beta_{1}$ becomes significantly different from zero in Figure 1 . The variable $X_{2}$ is much higher at $P_{N}$ than at $P_{M}$. Moreover the time evolution of $X_{2}$ is much slower than the time evolution of $X_{1}$. The stationary regime is not reached at the end of the pulse, as reported by the measured current chronograms of Figure 2 . 


\section{Here Figure 4.}

Let us study now the spatial distribution of the different quantities involved in the model. As mentioned in section 1, a similar issue has been addressed in [3], where simulations were performed in the case of irreversible electroporation. The problem in [3] is close to the our numerical setup shown in Schematic 2: a 2D geometry is considered with two needles of diameter $0.5 \mathrm{~mm}$ separated by a distance of $10 \mathrm{~mm}$. A V/d-ratio EF of $1500 \mathrm{~V} / \mathrm{cm}$ was chosen in the simulation in order to study irreversible electroporation. Among all the situations studied in the present paper, the configuration with the diameter of the needles $\varnothing=0.7 \mathrm{~mm}$ and the $\mathrm{V} / \mathrm{d}$-ratio $\mathrm{EF}$ of $1375 \mathrm{~V} / \mathrm{cm}$ is the closest. Figure 5 shows for this configuration the spatial distribution of the electric field at the tissue scale, as well as the spatial distribution of the amplitude of the homogenised TMP at the tissue scale $v_{m}$ and both electroporation processes $X_{1}$ and $X_{2}$. To make a meaningful comparison, results are shown at $t=1 \mu \mathrm{s}, 4.6 \mu \mathrm{s}, 21 \mu \mathrm{s}$ and $99 \mu \mathrm{s}$, which are the time points displayed in the fifth figure of [3].

\section{Here Figure 5.}

At the beginning of the pulse $t=1 \mu \mathrm{s}$, the electric field magnitude is the largest near the electrodes and drops off quickly as the distance increases. At $t=4.6 \mu \mathrm{s}$, the electric field distribution is slightly modified. The region in the neighborhood of the electrodes is already electroporated in a larger extent than in the middle of two electrodes (see the time evolution of $X_{1}$ in Figures $4 \mathrm{a}$ and $4 \mathrm{c}$ ). Hence, the tissue conductivity has increased locally. The gradient of conductivity induces a redistribution of the electric field that tends to become more uniform, as already pointed out in [3]. This numerical result is also supported by the necrosis area observed experimentally and displayed in the fifth figure of [8]. The necrotized tissue area coincides with the area that is delimited by a magnitude of the electric field equal to $700 \mathrm{~V} / \mathrm{cm}$ at $t=99 \mu \mathrm{s}$ in Figure 5 . It is worth noting that the same electric field threshold was obtained in [3] with a dynamic model and in [8] with a static model.

At $t=21$ and $99 \mu \mathrm{s}$, there are some changes in Figure 5 that do not appear in the simulation shown in [3]. The dynamic model in [3] is based on Krassowska's model that only accounts for the first dynamic, as discussed in section 4.1. In our model, the changes in Figure 5 at $t=21$ and $99 \mu$ s are due to the increase of $X_{2}$ (see the time evolution of $X_{2}$ in Figures $4 \mathrm{~b}$ and $4 \mathrm{~d}$ ). The distribution of $X_{2}$ is mainly located around the needles. It further increases the tissue conductivity in this region. This change has nearly no effect on the electric field distribution, but it modifies strongly the amplitide of the homogenised TMP at the tissue scale: at the end of the pulse, $v_{m}$ becomes smaller near the electrodes compared with its value in the middle of the electrodes (see also Figure 3 ). The drop of $v_{m}$ can be seen from the electric circuit of Schematic 1. The strong increase of the membrane conductivity implies that the resistance $R_{m}$ decreases strongly, which leads to a decrease of the voltage defined across $R_{m}$. A similar result is observed in the fifth figure in [3] between

$t=1 \mu \mathrm{s}$ and $4.6 \mu \mathrm{s}$. The observation is less salient for the two other time points in [3] since only the first dynamic of electroporation was considered. This result is also in accordance with simulations performed at the cell scale as discussed in section 4.2. 
Our modeling can thus be seen as an extension of the results of [3], in which the problem is formulated in terms of circuit elements derived from a cell model with a rectangular shape. In the present paper, the electric circuit is correlated to the electric circuit derived from a single spherical cell exposed to a uniform external field (see Appendix A), and the contribution of the extracellular medium is added separately. Unlike [3] our modeling introduces parameters at the tissue scale thanks to the definition of homogenised quantities ; moreover the tissue is considered as a continuous medium.

\section{Interpretation of the phenomenological model}

In this section, we provide some interpretations of the phenomenological model in terms of pore creation and pore growth, in order to link the phenomenological approach to the Krassowska et al.'s theory.

\subsection{Creation of pores}

The first dynamic described by the evolution of the function $X_{1}(t)$ can be related to the creation of pores. A model for the evolution of the pores density has been proposed in [1]: here, it is referred to as Krassowska's model. In [1], the pores density $N(t)$ is assumed to be governed by the following equation

$$
\frac{d N}{d t}=\alpha e^{\left(v_{m} / V_{e p}\right)^{2}}\left(1-\frac{N}{N_{0}} e^{-q\left(v_{m} / V_{e p}\right)^{2}}\right)
$$

where $V_{e p}$ the characteristic threshold voltage of the electroporation process. $N_{0}$ is the initial number of pores when $v_{m}=0 \mathrm{~V} . \alpha$ and $q$ are nonmeasurable parameters.

Denoting by $N_{\max }$ the maximal density of pores, one can define a function $X \in[0,1]$ similar to $X_{1}$ related to the pore creation

$$
X=\frac{N-N_{0}}{N_{\max }-N_{0}}
$$

The maximum fraction of the membrane surface occupied by pores has been estimated to $10^{-3}$ in [35] and the typical size of a created pore has been set to $r_{\text {pore }}=0.7 \mathrm{~nm}$ in [1]. Using these numerical values, one finds $N_{\max }=10^{-3} / \pi r_{\text {pore }}^{2}=10^{11} \mathrm{~cm}^{-2}$. However this value is too high compared with the pore density computed in [1]: this is why we set $N_{\max }=10^{10} \mathrm{~cm}^{-2}$ in our simulations. Moreover, the typical value for $N_{0}$ has been set to $1.5 \times 10^{5} \mathrm{~cm}^{-2}$ in [1] Thus $N_{\text {max }} \gg N_{0}$ and equation (15) can be rewritten

$$
N \approx N_{\max } X+N_{0}
$$

Combining (14) and (16), one finds

$$
\frac{d X}{d t}=\frac{\beta\left(v_{m}\right)-X}{\tau\left(v_{m}\right)},
$$


where

$$
\beta\left(v_{m}\right)=\frac{N_{0}}{N_{\max }}\left(e^{q\left(v_{m} / V_{e p}\right)^{2}}-1\right)
$$

and

$$
\tau\left(v_{m}\right)=\frac{N_{0}}{\alpha} e^{(q-1)\left(v_{m} / V_{e p}\right)^{2}} .
$$

The density of current $J_{e p}$ that flows through the membrane is given by

$$
J_{e p}=N G_{\text {pore }}\left(v_{m}\right) v_{m}
$$

where $G_{\text {pore }}$ is the conductance of a pore. It can be written

$$
G_{\text {pore }}\left(v_{m}\right)=\frac{\sigma_{\text {pore }} \pi r_{\text {pore }}^{2}}{h} g\left(v_{m}\right)
$$

where the first term is the usual conductance related to a cylinder of radius $r_{\text {pore }}$ and height $h$ with a conductivity $\sigma_{\text {pore }}$. The second term is the non linear term due to the electrodiffusion inside the pores

$$
g\left(v_{m}\right)=\frac{e^{\nu_{m}}-1}{\frac{w_{0} e^{\left(w_{0}-n \nu_{m}\right)}-n \nu_{m}}{w_{0}-n \nu_{m}} e^{\nu_{m}}-\frac{w_{0} e^{\left(w_{0}+n \nu_{m}\right)}+n \nu_{m}}{w_{0}+n \nu_{m}}}
$$

where $\nu_{m}=F v_{m} / R T, w_{0}$ is the barrier energy within the pore and $n$ the relative entrance length of pores.

One can then define the conductivity for the membrane $\sigma_{e p}$ at the cell scale due to electroporation

$$
\sigma_{e p}=\frac{J_{e p}}{v_{m} / h}
$$

The total conductivity of the membrane is the sum of $\sigma_{e p}$ and the conductivity of the membrane when there is no pore. At the tissue scale, the equivalent conductivity for the membrane $\sigma_{m}^{\prime}$ can be derived by introducing the renormalization factor $\eta_{m}$. Combining the equations (16), (18), (19) and (21), the expression of $\sigma_{m}^{\prime}$ reads

$$
\sigma_{m}^{\prime}=\sigma_{m 0}+\sigma_{m 1}^{\prime} g\left(v_{m}\right) X\left(v_{m}, t\right)
$$

where $\sigma_{m 1}^{\prime}=\eta_{m} N_{\text {max }} \sigma_{\text {pore }} \pi r_{\text {pore }}^{2}$.

The renormalization factor $\eta_{m}$ applies in the same way to the conductivity and the permittivity of the membrane. Thus, data on the membrane permittivity can be exploited to evaluate $\eta_{m}$ : using a relative permittivity of the membrane equal to $\epsilon_{m}=60000$ at the tissue scale (see Table 1, case $\varnothing=0.7 \mathrm{~mm}$ ) and equal to $\epsilon_{m}^{\text {cell }}=2$ at the cell scale [28], one finds $\eta_{m}=\epsilon_{m} / \epsilon_{m}^{\text {cell }}=30000$. Using in addition $N_{\text {max }}=10^{10} \mathrm{~cm}^{-2}, \sigma_{\text {pore }}=13 \mathrm{mS} / \mathrm{cm}$ and $r_{\text {pore }}=0.7 \mathrm{~nm}$, one finds $\sigma_{m 1}^{\prime}=6.0 \mathrm{~S} / \mathrm{m}$ which is in the range of values set for $\sigma_{m 1}$ in Table 1. There is also the term $g$ in equation (22) which varies between 0.45 and 0.85 
for $v_{m} \in[0,1] \mathrm{V}$. Note that $\sigma_{m 0}$ is the same quantity as in equation (9) because the term $\eta N_{0} \sigma_{\text {pore }} \pi r_{\text {pore }}^{2} g\left(v_{m}\right) \leq 90 \mu \mathrm{S} / \mathrm{m}$ has been neglected in equation (22): it is much smaller than the value of $\sigma_{m 0}$ given in Table 1.

The membrane conductivity at any time is given by equation (22) while the evolution of $X(t)$ is governed by equation (17). Table 2 reports the values of the different parameters. These parameters are given in [1], except $V_{e p}$ and $w_{0}$ that have been decreased by a factor between 2 and 3 to obtain a better fit with the experimental data. There are 7 independent parameters in Krassowska's model, while only 4 parameters are introduced in the phenomenological model for the first dynamic, therefore the parameters of the Krassowska's model are linked, which increases the complexity of the calibration, unlike our phenomenological approach.

\section{Here Table 2.}

In Figure 2(b), the dashed line corresponds to the chronograms of currents computed with the Krassowska's model in the case $\varnothing=0.7 \mathrm{~mm}$. The model of the pores creation enables to predict the first dynamic ${ }^{4}$ with an accuracy similar to the phenomenological approach, but it fails to describe the second dynamics: the chronograms are flat as soon as the pores are created.

Figure 6 shows the amplitude of the homogenised TMP at the tissue level computed from the phenomenological and Krassowska's models during the first microseconds at the point $P_{M}$. A good agreement is observed between the two models. Using Krassowska's model, the amplitude of the homogenised TMP at the tissue scale reaches a value between 0.54 and $0.56 \mathrm{~V}$ except for the $\mathrm{V} / \mathrm{d}$-ratio $\mathrm{EF}$ of $375 \mathrm{~V} / \mathrm{cm}$ : this value is equal to about $5 V_{e p}$ which is close to the critical voltage $4 V_{e p}$ considered in [1]. Using the phenomenological model, the maximum value for the homogenised TMP at the tissue scale is included between 0.49 and $0.53 \mathrm{~V}$, except for the $\mathrm{V} / \mathrm{d}$-ratio $\mathrm{EF}$ of $375 \mathrm{~V} / \mathrm{cm}$, which is close to the previous value.

\section{Here Figure 6.}

Thus, the phenomenological model - equations (9), (10) and (11) - enables to reproduce the first dynamic of the electroporation predicted by Krassowska's model - equations (17) and (22). This proves that a threshold effect can be introduced in the electroporation modeling, even if it is not explicitly contained in the model of pores creation.

\subsection{Growth of pores}

The second dynamic described by the function $X_{2}(t)$ can be related to the increase of the pores size. A dynamic model of the distribution of the pore radii has been proposed in [4], which is referred to as the second Krassowska's model. In the numerical case proposed in [4], it comes out that after the capacitive charge of the membrane $(t<0.5 \mu \mathrm{s})$, two stages

\footnotetext{
${ }^{4}$ Note that here again one observes a discrepancy between the simulations and the measurements for the $\mathrm{V} / \mathrm{d}$-ratio EF of $1125 \mathrm{~V} / \mathrm{cm}$.
} 
are identified in the electroporation process: the creation of a large number of small pores $(0.5 \mu \mathrm{s}<t<1.5 \mu \mathrm{s})$ and then the evolution of the pore radii $(t>1.5 \mu \mathrm{s})$.

Denote by $n(r)$ the function that describes the distribution of pores with respect to their radius $r$. In those conditions, the total pore density $N$ is given by

$$
N=\int_{r_{\text {pore }}}^{+\infty} n(r) d r
$$

where $r_{\text {pore }}$ is the minimum radius of the pores when they are formed. In [4] the pore radius resistance is given by

$$
R(r)=\frac{h}{\sigma_{\text {pore }} \pi r^{2}}+\frac{1}{2 \sigma_{\text {pore }} r} .
$$

The first term is the resistance of the pore given by equation (19) when the non linear term $g\left(v_{m}\right)$ due to electrodiffusion is neglected. The second term gives the resistance at the input of the pore. The expression of the current density $J_{e p}$, which flows through the membrane becomes more complex compared with equation (18):

$$
J_{e p}=\int_{r_{p o r e}}^{+\infty} \frac{n(r)}{R(r)} d r \times v_{m} .
$$

However, the numerical studies proposed in [4] lead to two populations of pores. During the pulse delivery, most of the pores remain small with a radius around $1 \mathrm{~nm}$, while a few of them grow with an average size that reaches about $20 \mathrm{~nm}$. Therefore the above integral can be split between the current density related to small pores, as given by equation (18) and the current density due to the emergence of the large pored. To compute the evolution of the second population at the tissue scale, the distribution $n(r, t)$ defined at any spatial point inside the tissue is calculated from a set of ordinary differential equations similar to the one provided in [4]. However, the maximum increase of the membrane conductivity can be derived more straightforwardly.

Assume that a pore is formed with a radius $r_{\text {pore }}$. The variation of the pore conductance $\Delta G$ due to the change of the pore radius $r$ can be deduced from equation (24)

$$
\Delta G(r)=\frac{1}{R(r)}-\frac{1}{R\left(r_{\text {pore }}\right)}
$$

Following the same approach as for the calculation of $\sigma_{m 1}^{\prime}$, one finds that the increase of the membrane conductivity at the tissue scale is given by $\sigma_{m 2}^{\prime}=\eta_{m} p N_{\max } \Delta G h$, where $p$ is the fraction of pores that reach a large size. Simulations performed in [4] show that $2.2 \%$ of the created pores go on growing during the pulse: we set $p=2 \%$ in the numerical application. Using in addition $\eta_{m}=30000, N_{\max }=10^{10} \mathrm{~cm}^{-2}, r=20 \mathrm{~nm}, r_{\text {pore }}=0.7 \mathrm{~nm}, \sigma_{\text {pore }}=$ $13 \mathrm{mS} / \mathrm{cm}$ and $h=5 \mathrm{~nm}$, one finds $\sigma_{m 2}^{\prime}=13.3 \mathrm{~S} / \mathrm{m}$ that is to say about twice the value of $\sigma_{m 1}^{\prime}$. This numerical result is consistent with the parameters set in the phenomenological model: $13.3 \mathrm{~S} / \mathrm{m}$ is in the range of values set for $\sigma_{m 2}$ in Table 1 , which are themselves equal to the values set for $\sigma_{m 1}$ multiplied by a factor between 2 and 3 . 
In addition, the decrease of the homogenised TMP at the tissue scale computed from the phenomenological model during the second dynamic (see Figures 3 and 5) is also predicted by the simulations performed at the cell scale using the second Krassowska's model. More precisely, numerical results given in [4] show that the amplitude of the TMP globally decreases along the cell circumference during the pulse: the TMP profile is sinusoidal at the very beginning. It becomes flatter as the time increases because of the evolution of the pore radii.

\section{Conclusion}

In this paper, we have proposed a new dynamical model of tissue electroporation. Considering two current densities from cells and extracellular matrix, we identify the macroscopic contribution of the membranes and derive the amplitude of the homogenised TMP. Adapting the phenomenological electroporation model of Leguèbe et al., we calibrate the tissue model with experimental data, making appear two steps in the tissue electroporation process, as for cells. The new insight of the model lies in the definition of the amplitude of the homogenised TMP which makes it possible to use cell scale models for tissue modeling purpose. Our approach is tightly linked to the numerical homogenisation strategy.

Our model can be completed in order to describe other dynamics observed in electroporation experiments once the voltage is turned off [16]. Resealing process can be introduced considering a possible decrease of both $X_{1}$ and $X_{2}$, which has been ignored in the present paper. Besides, another dynamic should be introduced as proposed in [7] to take into account diffusion of lipids along the cell membrane occurring between pulses when several pulses are delivered.

Furthermore, the few deviations observed between experiments and simulations show limitations of the present model. First, the response of a healthy tissue to the pulse delivery is described by a Debye dispersion while Cole-Cole dispersion seems more appropriate. The model accuracy could also be improved by the modeling the electrochemical reactions near the electrodes. This phenomenon could impact on the effective size of the needles, leading to different field distribution. However, our model provides a validated first-step towards accurate tissue electroporation modeling.

It is also worth noting that our model has been validated for one pulse only. Forthcoming works will be devoted to validate or adapt the model to the typically used trains of 8 -as used for electrochemotherapy- or 90 pulses - as used in irreversible electroporation. The

long term goal is to clarify how the output of these models correlates with clinical results of electroporation-based therapies.

\section{Acknowledgements}

The authors acknowledge funding support from the ITMO Cancer in the frame of the Plan Cancer 2015-2019 (projects DYNAMO PC201517, and NUMEP PC201615). The work has also been supported by CNRS under the PEPS project ERACHEK. This research has been carried out within the scope of the LEA EBAM and the Inria associate team Num4SEP. We also acknowledge the LabEx PRIMES (ANR-11LABX-0063). 


\section{Appendix A. Relation between the electric models at the tissue and cell scales}

Consider a single cell in suspension exposed to an external electric field $E_{0}$, as shown in Schematic 3 .

\section{Here Schematic 3.}

The TMP $v_{m}^{\text {cell }}$ for a step excitation of the external electric field is given in [36] by

$$
v_{m}^{\text {cell }}(t, \theta)=\gamma E_{0} r \cos (\theta)\left(1-e^{-t / \tau_{\text {cell }}}\right)
$$

where

$$
\gamma=\frac{3 \sigma_{0}\left[3 h r^{2} \sigma_{c}^{\text {cell }}+\left(3 h^{2} r-h^{3}\right)\left(\sigma_{m}^{\text {cell }}-\sigma_{c}^{\text {cell }}\right)\right]}{2 r^{3}\left(\sigma_{m}^{\text {cell }}+2 \sigma_{0}\right)\left(\sigma_{m}^{\text {cell }}+\sigma_{c}^{\text {cell }} / 2\right)-2(r-h)^{3}\left(\sigma_{0}-\sigma_{m}^{\text {cell }}\right)\left(\sigma_{c}^{\text {cell }}-\sigma_{m}^{\text {cell }}\right)}
$$

and

$$
\tau_{\text {cell }}=\frac{r C_{m}^{\text {cell }}}{2 \sigma_{0} \sigma_{c}^{\text {cell }} /\left(2 \sigma_{0}+\sigma_{c}^{\text {cell }}\right)+\sigma_{m}^{\text {cell }} r / h}
$$

with $C_{m}^{\text {cell }}=\epsilon_{m}^{\text {cell }} / h$.

It is worth noting that the time evolution in equation (A.1) is due to Maxwell-Wagner effects at the membrane interface and it fits a Debye relaxation [37].

Introducing $R_{c}^{\text {cell }}=r / \sigma_{c}^{\text {cell }}, R_{m}^{\text {cell }}=h / \sigma_{m}^{\text {cell }}$ and $R_{0}=r /\left(2 \sigma_{0}\right)$, equation (A.3) can be rewritten as

$$
\tau_{\text {cell }}=\frac{C_{m}^{\text {cell }}}{1 /\left(R_{0}+R_{c}^{\text {cell }}\right)+1 / R_{m}^{\text {cell }}}
$$

Furthermore, assuming that $r / h \gg 1$ and $\sigma_{m}^{\text {cell }} \leq \sigma_{c}^{\text {cell }}, \sigma_{0}$, equation (A.2) can be simplified to

$$
\gamma=\frac{3}{2} \frac{R_{m}^{\text {cell }}}{R_{0}+R_{c}^{\text {cell }}+R_{m}^{\text {cell }}}
$$

Thus, equations (A.1), (A.4) and (A.5) can rigorously be derived from the equivalent circuit shown in Schematic 4. Note that the factor $3 r / 2$ in the expression of the voltage $v^{\text {cell }}$ can be interpreted as follows. If one considers the radius $r$ of the cell, the voltage $v^{\text {cell }}$ could a priori be given by $r E_{0} \cos (\theta)$. But, the extracellular medium influences the field induced inside the cell: in the formulas $R_{c}^{\text {cell }}=r / \sigma_{c}^{\text {cell }}$ and $R_{0}=r /\left(2 \sigma_{0}\right)$, the effective dimension of the intracellular medium is $r$ while the effective dimension of the extracellular medium is $r / 2$; hence, the total effective length is $r+r / 2=3 r / 2$.

\section{Here Schematic 4.}

The model considered at the tissue scale in Schematic 1 is partly correlated to the model derived at the cell scale in Schematic 4. However, there are a few notable differences: 
- No dependence on $\theta$ is considered at the tissue scale. This is an inherent limitation of the equivalent circuit given in Schematic 1. The electroporation process is known to induce changes non uniformly along the membrane circumference. Note that in this case the solution of the problem cannot be rigorously represented by the simple circuit given in Schematic 4. Taking into account the changes that appear locally on the membrane would require a more elaborated homogenized model, and the simulation would require much more numerical resources to solve the local problem. Thus, the model at the tissue scale given in Schematic 1 would rather give a mean effect at the macroscopic scale.

- The element $R_{c}^{\text {cell }}+R_{0}$ is replaced by $R_{c}$ in the equivalent circuit of the tissue. Roughly, it is expected that the extracellular medium would occupy less space when the cells are packed compared to the case of a single cell in suspension. However, the term $R_{c}$ could include the part of the conductive extracellular medium that is in the neighborhood of the cells.

- No factor $3 / 2$ is taken into account in the relation between the macroscopic electric field and the voltage considered across the cell. This is a consequence of the previous assumption in which the cells are supposed to be close each others. However, the electric circuit in Schematic 1 is correlated to an entire cell; in this way, it can be viewed as the series connection of two circuits as shown in Schematic 4.

- A resistance $R_{e}$ is added to take into account the extracellular medium. There is no connection between $R_{e}$ and $R_{0}$ : the current that flows through $R_{e}$ is the extracellular current that does not flow through the cells.

\section{Appendix B. Renormalization procedure to derive the electric properties at the tissue scale}

Consider a sample of biological tissue placed between two metallic plates of surface $S$ and separated by a distance $l$. Assume that an appropriate circuit to model the frequency response of the tissue is represented in Schematic 1. Let $v$ define the voltage between both metallic plates, while $i$ defines the current that flows through one metallic plate. The standard circuit laws lead to

$$
\begin{aligned}
& i=i_{\text {cell }}+i_{e} \\
& i_{\text {cell }}=2\left(C_{m} \frac{d u_{m}}{d t}+u_{m} / R_{m}\right)=\left(v-2 u_{m}\right) / R_{c} \\
& i_{e}=v / R_{e}
\end{aligned}
$$

Denote by $v_{c}=v-2 u_{m}$ and replace $2 u_{m}$ by $v-v_{c}$ in (B.2) to obtain

$$
i_{c e l l}=C_{m} \frac{d v}{d t}+v / R_{m}-\left(C_{m} \frac{d v_{c}}{d t}+v_{c} / R_{m}\right)=\frac{v_{c}}{R_{c}} .
$$


Since $v=R_{e} i_{e}$, and $v_{c}=R_{c} i_{c e l l}$, one infers

$$
C_{m} R_{c} \frac{d i_{c e l l}}{d t}+\left(1+\frac{R_{c}}{R_{m}}\right) i_{c e l l}=R_{e} C_{m} \frac{d i_{e}}{d t}+\frac{R_{e}}{R_{m}} i_{e}
$$

Then equation (2) is obtained by neglecting the displacement current in the extracellular medium. At the tissue scale, one can define the electric field $\nabla \varphi$ and the current density $J$ uniformly distributed between both metallic plates. By introducing the dimensions of the sample, one finds

$$
J=\frac{i}{S} \quad \nabla \varphi=\frac{v}{l} \quad R=\frac{l}{\sigma S} \quad C=\frac{\epsilon S}{l}
$$

where $\sigma$ and $\epsilon$ are the equivalent conductivity and permittivity at the tissue scale related to the resistances $R$ and capacitances $C$ of the electric circuit.

Then equation (6) is obtained introducing the renormalized quantities defined by equation (B.4) into equation (2).

It should be mentioned that the conductivity and permittivity defined at the tissue scale are different from the ones defined at the cell scale. For instance, the value for the relative permittivity for the membrane at the tissue scale is larger than 10000 (see Table 1) while the value at the cell scale does not exceed a few units. This is due to the fact that the membrane thickness is small $(\mathrm{nm})$ compared to the cell size $(\mu \mathrm{m})$. Besides, the conductivity and permittivity defined at the tissue scale in equation (B.4) should be estimated using impedancemetry measurements performed on tissues (see for example [38]), rather than using the features of a single cell. Thus, some characteristics of the tissue could be taken into account.

Furthermore, a homogenised TMP $v_{m}$ can be defined at the tissue scale. It is worth noting that this TMP is an equivalent quantity: it does not describe the value of the TMP for a given position on the circumference of a single cell in a tissue, but rather a mean effect on cells into the tissue.

The homogenised TMP at the tissue scale $v_{m}$ is related to the voltage $u_{m}$ defined in Schematic 1. Using circuit laws, one finds

$$
u_{m}=\frac{1}{2}\left(v-R_{c} i_{c e l l}\right)
$$

Then, the application of the renormalization defined in equation (B.4) gives

$$
u_{m}=\frac{1}{2} l\left\|\nabla \varphi-\frac{\mathbf{J}_{c e l l}}{\sigma_{c}}\right\|
$$

Finally, the homogenised TMP at the tissue scale $v_{m}$ given in equation (8) can be derived by introducing the real size of a biological cell $l=d_{c}$ in equation (B.6). 
[1] K. A. DeBruin, W. Krassowska, Modeling electroporation in a single cell: effects of field strength and rest potential, Biophysical Journal, Vol. 77, pp. 1213-1224, 1999.

[2] T. R. Gowrishankar, A. T. Esser, Z. Vasilkoski, K. C. Smith, J. C. Weaver, Microdosimetry for conventional and supra-electroporation in cells with organelles, Biochemical and Biophysical Research Communications, Vol. 341, pp. 1266-1276, 2006.

[3] A. T. Esser, K. C. Smith, T. R. Gowrishankar, J. C. Weaver, Towards solid tumor treatment by irreversible electroporation: Intrinsic redistribution of fields and currents in tissue, Technology in Cancer Research and Treatment 6 (4) (2007) 261-274.

[4] W. Krassowska, P. D. Filev, Modeling electroporation in a single cell, Biophysical Journal, Vol. 92, pp. 404-417, 2007.

[5] J. Li, H. Lin, Numerical simulation of molecular uptake via electroporation, Bioelectrochemistry, Vol. 82, pp. 10-21, 2011.

[6] O. Kavian, M. Leguèbe, C. Poignard, L. Weynans, Classical electropermeabilization modelling at the cell scale, Journal of Mathematical Biology, Vol. 68, pp. 235-265, 2014.

[7] M. Leguèbe, A. Silve, L. Mir, C. Poignard, Conducting and permeable states of cell membrane submitted to high voltage pulses: Mathematical and numerical studies validated by the experiments,, Journal of Theoretical Biology, Vol. 360, pp. 83-94, 2014.

[8] D. Sel, D. Cukjati, D. Batiuskaite, T. Slivnik, L. M. Mir, D. Miklavčič, Sequential finite element model of tissue electropermeabilization, Transaction on Biomedical Engineering, Vol. 52, No. 5, pp. 816-827, 2005.

[9] A. G. Pakhomov, D. Miklavcic, M. S. Markov, Advanced electroporation techniques in biology and medicine, CRC Press, 2010.

[10] R. E. Neal, J. L. Millar, H. Kavnoudias, P. Royce, F. Rosenfeldt, A. Pham, R. Smith, R. V. Davalos, K. R. Thomson, In vivo characterization and numerical simulation of prostate properties for non-thermal irreversible electroporation ablation, The Prostate 74 (5) (2014) 458-468. doi:10.1002/pros.22760.

URL http://dx.doi.org/10.1002/pros. 22760

[11] R. E. Neal, P. A. Garcia, H. Kavnoudias, F. Rosenfeldt, C. A. Mclean, V. Earl, J. Bergman, R. V. Davalos, K. R. Thomson, In vivo irreversible electroporation kidney ablation: Experimentally correlated numerical models, IEEE Transactions on Biomedical Engineering 62 (2) (2015) 561-569. doi:10.1109/TBME.2014.2360374.

[12] A. Ivorra, B. Al-Sakere, B. Rubinsky, L. M. Mir, In vivo electrical conductivity measurements during and after tumor electroporation: conductivity changes reflect the treatment outcome, Physics in Medecine and Biology, Vol. 54, pp. 5949-5963, 2009. 
[13] S. Corovič, I. Lackovič, P. Sustarič, T.Sustar, T. Rodič, D. Miklavčič, Modeling of electric field distribution in tissues during electroporation, BioMedical Engineering, Online 12:16, 2013.

[14] R. E. Neal, P. A. Garcia, H. Kavnoudias, F. Rosenfeldt, C. A. Mclean, V. Earl, J. Bergman, R. V. Davalos, K. R. Thomson, In vivo irreversible electroporation kidney ablation: experimentally correlated numerical models, IEEE Transactions on Biomedical Engineering 62 (2) (2015) 561-569.

[15] M. Marčan, B. Kos, D. Miklavčič, Effect of blood vessel segmentation on the outcome of electroporation-based treatments of liver tumors, PloS one 10 (5) (2015) e0125591.

[16] J. Teissié, M. Golzio, M. P. Rols, Mechanisms of cell membrane electropermeabilization: a minireview of our present (lack of?) knowledge, Biochimica and Biophysica Acta, No. 1724, pp. 270-280, 2005.

[17] J. Langus, M. Kranjc, B. Kos, T. Šuštar, D. Miklavčič, Dynamic finite-element model for efficient modelling of electric currents in electroporated tissue, Scientific reports 6 (2016) 26409.

[18] A. Abdulle, M. Huber, Finite element heterogeneous multiscale method for nonlinear monotone parabolic homogenization problems, ESAIM:M2AN.

[19] F. Maglietti, S. Michinski, N. Olaiz, M. Castro, C. Suárez, G. Marshall, The role of ph fronts in tissue electroporation based treatments, PloS one 8 (11) (2013) e80167.

[20] M. K. Stehling, E. Guenther, P. Mikus, N. Klein, L. Rubinsky, B. Rubinsky, Synergistic combination of electrolysis and electroporation for tissue ablation, PLOS ONE 11 (2) (2016) 1-23. doi:10.1371/journal.pone.0148317.

URL https://doi.org/10.1371/journal .pone.0148317

[21] P. C. Franzone, G. Savaré, Degenerate evolution systems modeling the cardiac electric field at micro-and macroscopic level, in: Evolution equations, semigroups and functional analysis, Springer, 2002, pp. 49-78.

[22] M. Amar, D. Andreucci, R. Gianni, P. Bisegna, Evolution and memory effects in the homogenization limit for electrical conduction in biological tissues, Mathematical Models and Methods in Applied Sciences 14 (09) (2004) 1261-1295.

[23] L. Cima, L. M. Mir, Macroscopic characterization of cell electroporation in biological tissue based on electrical measurements, Applied Physics Letters, Vol. 85, No 19, 2004.

[24] L. A. Dissado, A fractal interpretation of the dielectric response of animal tissues, Physics in Medecine and Biology, Vol. 35, No 11, pp. 1487-1503, 1990.

[25] D. Miklavčič, N. Pavselj, F. X. Hart, Electric properties of tissues, Wiley Encyclopedia of Biomedical Engineering, 2006. 
[26] V. Raicu, T. Saibara, H. Enzan, A. Irimajiri, Dielectric properties of rat liver in vivo: analysis by modeling hepatocytes in the tissue architecture, Bioelectrochemistry and Bioenergetics 47 (1998) 333-342.

[27] C. Gabriel, Handbook of Biological Effects of Electromagnetic Fields, 2007.

[28] J. C. Weaver, Y. A. Chizmadzhev, Theory of electroporation: A review, Bioelectrochemistry and Bioenergetics, Vol. 41, pp. 135-160, 1996.

[29] T. R. Gowrishankar, J. C. Weaver, An approach to electrical modeling of single and multiple cells, Proceedings of the National Academy of Sciences USA, Vol. 100, No 6, pp. 3203-3208, 2003.

[30] D. Cukjati, D. Batiuskaite, F. Andre, D. Miklavčič, L. M. Mir, Real time electroporation control for accurate and safe in vivo non-viral gene therapy, Bioelectrochemistry, Vol. 70, pp. 501-507, 2007.

[31] L. M. Mir, C. Poignard, R. Scorretti, A. Silve, D. Voyer, Dynamic modeling of electroporation for the computation of the electric field distribution inside biological tissues during the applicat,on of the pulse voltage,, 1srt World Congress on Electroporation, in IFMBE Proceedings, Vol. 53, pp. 211-214, 2015.

[32] C. T. Kelley, Iterative Methods for Linear and Nonlinear Equations, Chapter 8, Global Convergence, Society for Industrial and Applied Mathematics, 1995.

[33] J. Pommier, Y. Renard, Getfem++. An open source generic $\mathrm{C}^{++}$it library for finite element methods, http://download.gna.org/getfem/html/homepage.

[34] R. D. Stoy, K. R. Foster, H. P. Schwan, Dielectric properties of mammalian tissues from $0.1 \mathrm{~Hz}$ to $100 \mathrm{MHz}$ : a summary of recent data, Physics in Medecine and Biology, Vol. 27, pp. 501-513, 1982 .

[35] K. A. DeBruin, W. Krassowska, Electroporation and shock-induced transmembrane potential in a cardiac fiber during defibrillation strength shocks, Annals of Biomedical Engineering, Vol. 26, pp. 584-596, 1998.

[36] T. Kotnik, D. Miklavčič, T. Slivnik, Time course of transmembrane voltage induced by time-varying electric fields: a method for theoretical analysis and its application, Bioelectrochemistry and Bioenergetics, Vol. 45, pp. 3-16, 1998.

[37] S. G. O. G. Martinsen, H. P. Schwan, Encyclopedia of surface and colloid science, 2002.

[38] V. Raicu, T. Saibara, A. Irimajiri, Dielectric properties of rat liver in vivo: a noninvasive approach using an open-ended coaxial probe at audiorradio frequencies, Bioelectrochemistry and Bioenergetics 47 (1998) 325-332. 


\section{List of schematic captions}

- Schematic 1: Equivalent circuit of a biological tissue as introduced in [31]. Note that there is an error in the first figure of [31]: there is no factor 2 for $C_{m}$ and $R_{m}$. If not, the model would not be consistent with the equations derived in rest of the paper. The resistance $R_{e}$ represents the conductive extracellular medium whereas the branch $R_{c}+R_{m} / / C_{m}$ represents the cell response. More precisely, the resistance $R_{c}$ is correlated to the cytoplasm medium whereas the capacitance $C_{m}$ in parallel with the resistance $R_{m}$ are correlated to the cell membrane. $v$ and $u_{m}$ are the voltages defined by the vertical arrows in specific parts of the circuit; $i, i_{\text {cell }}$ and $i_{e}$ are the currents that flow through specific parts of the circuit.

- Schematic 2: Mesh of the considered 2D problem, in the case $\varnothing=0.7 \mathrm{~mm}$. The point $P_{N}$ is positioned on the boundary of one needle and the point $P_{M}$ in the middle between the electrodes.

- Schematic 3: Model of a single cell. The cell is a sphere of radius $r$, enclosed by a membrane of uniform thickness $h$. The conductivity of the cytoplasm is denoted by $\sigma_{c}^{\text {cell }}$, the membrane conductivity is $\sigma_{m}^{\text {cell }}$ and the extracellular conductivity is $\sigma_{0}$. The membrane permittivity equals $\epsilon_{m}^{c e l l}$. The cell is embedded in the uniform external electric field $\mathbf{E}_{\mathbf{0}}$.

- Schematic 4: Equivalent electrical circuit of the single cell obtained from equations (A.1), (A.4) and (A.5). The capacitance $C_{m}^{\text {cell }}$ and the resistances $R_{c}^{\text {cell }}, R_{m}^{\text {cell }}$ and $R_{0}$ depend on the electric and geometric parameters defined in Schematic 3: $C_{m}^{\text {cell }}=\epsilon_{m}^{\text {cell }} / h, R_{c}^{\text {cell }}=r / \sigma_{c}^{\text {cell }}$, $R_{m}^{\text {cell }}=h / \sigma_{m}^{\text {cell }}$ and $R_{0}=r /\left(2 \sigma_{0}\right) . v_{m}^{\text {cell }}$ is the TMP and $v^{\text {cell }}$ the voltage defines for the whole circuit that involves the cell and the extracellular medium. 


\section{List of figure captions}

- Figure 1: Shape of the sigmoid functions. The blue continuous line represents $\beta_{1}$ given by equations (11) and the dashed red line represents $\beta_{2}$ given by (13) with the parameters reported in Table 1 in the case $\phi=0.7 \mathrm{~mm}$.

- Figure 2: Comparison between the experimental and the numerical chronograms of the currents with three sizes of the needles: (a) $\phi=0.3 \mathrm{~mm}$, (b) $\phi=0.7 \mathrm{~mm}$ and (c) $\phi=1.1 \mathrm{~mm}$. Dotted lines refer to the experimental current recorded during the first pulse in [8], continuous lines refer to the simulations of the phenomenological model with the parameters reported in Table 1 . In the case $\phi=0.7 \mathrm{~mm}$, dashed lines refer to the simulations of Krassowska's model with the parameters reported in Table 2.

- Figure 3: Evolution of the homogenised TMP at the tissue scale computed from the phenomenological model in the case $\phi=0.7 \mathrm{~mm}$ at the points: (a) $P_{N}$ and (b) $P_{M}$.

- Figure 4: Evolution of the functions $X_{1}$ and $X_{2}$ computed in the case $\phi=0.7 \mathrm{~mm}$ at the points $P_{M}$ and $P_{N}$ : (a) $X_{1}$ at $P_{N}$, (b) $X_{2}$ at $P_{N}$, (c) $X_{1}$ at $P_{M}$ and (d) $X_{2}$ at $P_{M}$.

- Figure 5: spatial distribution of the electric field, homogenised TMP at the tissue scale $v_{m}$ and both electroporation processes $X_{1}$ and $X_{2}$ in the case $\phi=0.7 \mathrm{~mm}$ and for the $\mathrm{V} / \mathrm{d}-$ ratio EF of $1375 \mathrm{~V} / \mathrm{cm}$.

- Figure 6: Comparison of the homogenised TMP at the tissue scale computed from the phenomenological model (continuous line) and Krassowska's model (dashed line) at the point $P_{M}$ in the case $\phi=0.7 \mathrm{~mm}$. 


\section{List of table captions}

- Table 1: Values of the model parameters for the three sizes of the needles. The first part of the table is related to the electrical properties of the tissue and the second part to the parameters of the phenomenological model of the electroporation process.

- Table 2: Values of the different parameters of Krassowska's model of the pores creation from [4]. 
Schematic 1

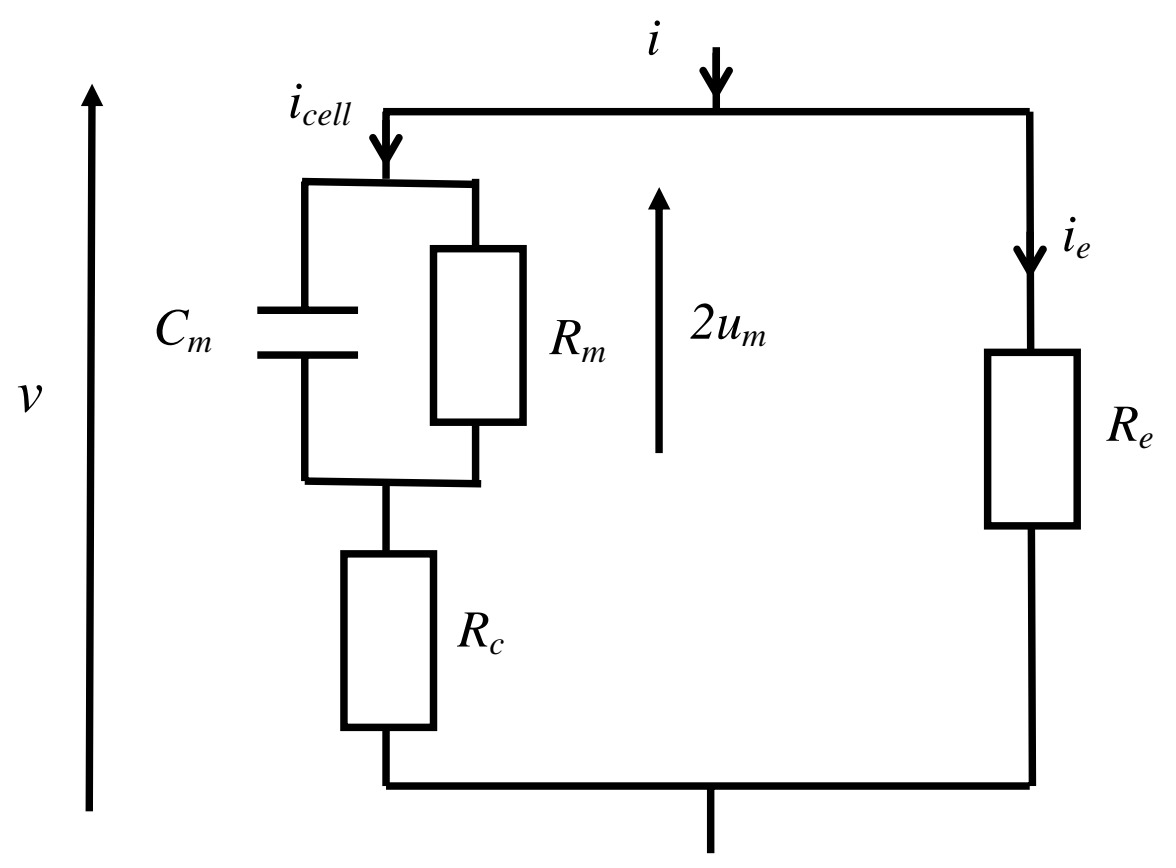


Schematic 2

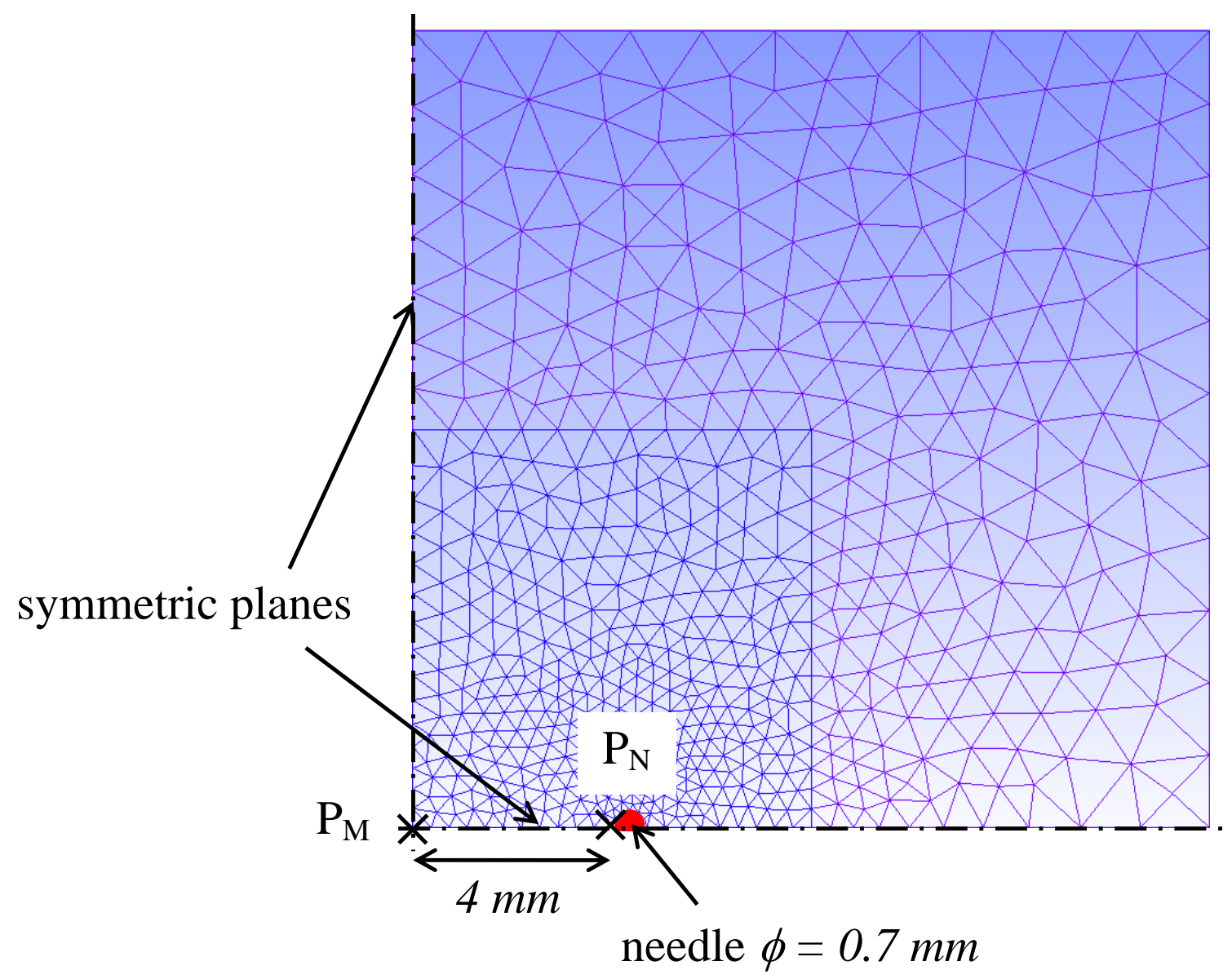


Schematic 3

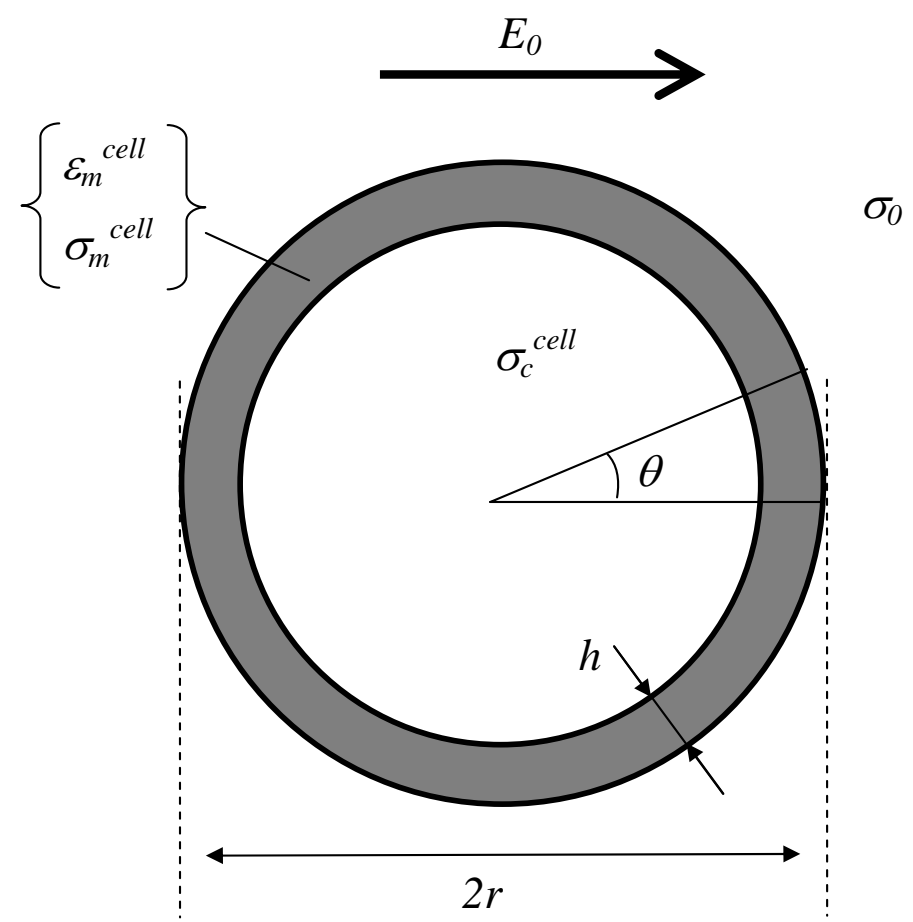


Schematic 4

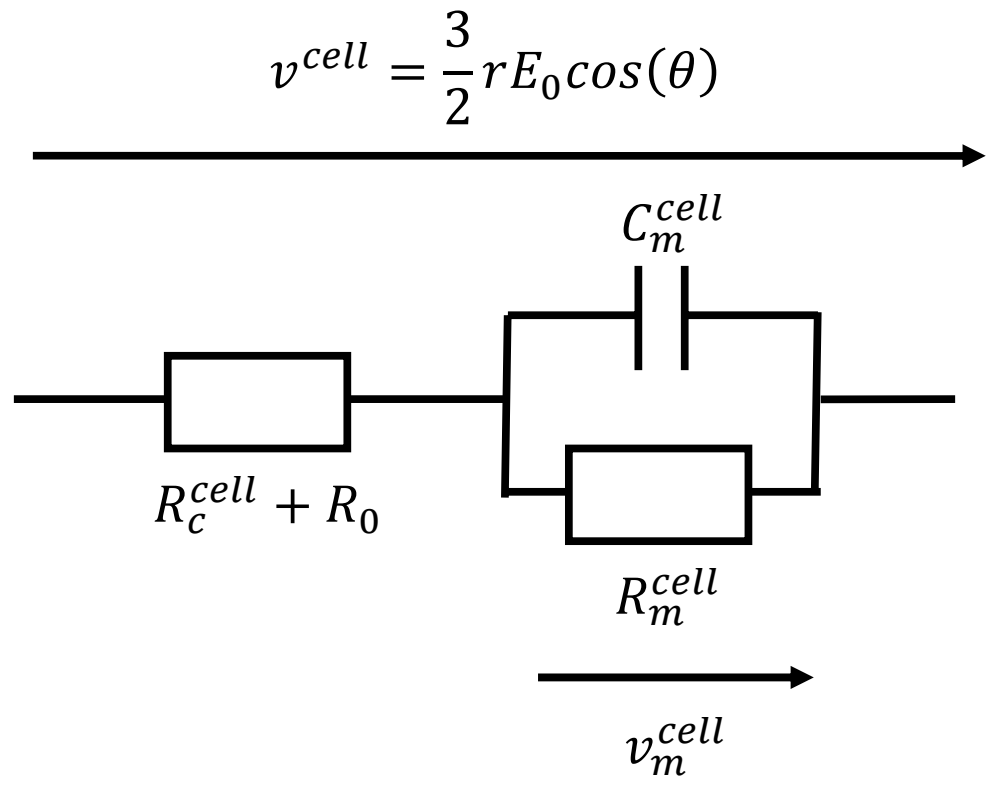


Figure 1

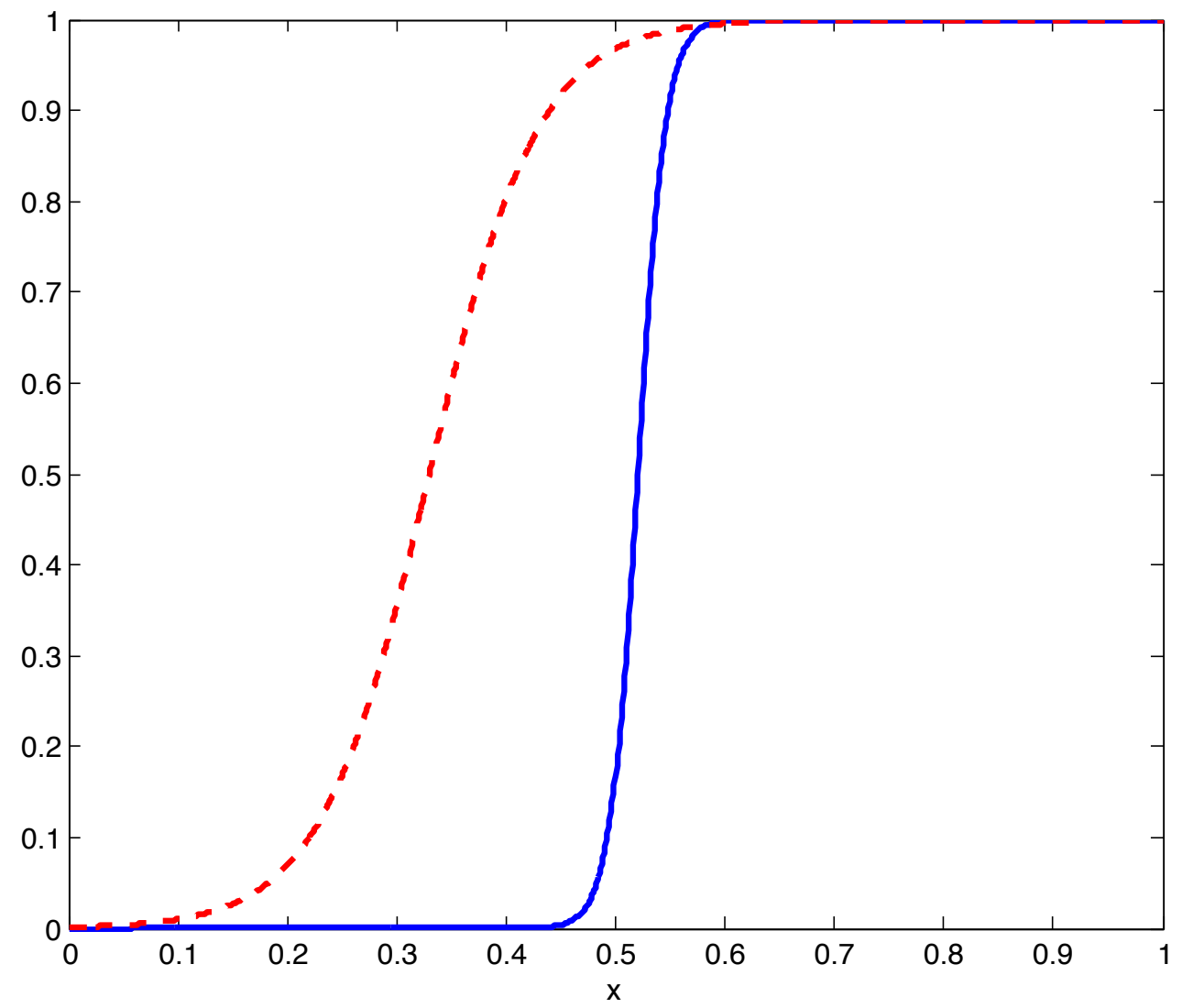


Figure 2

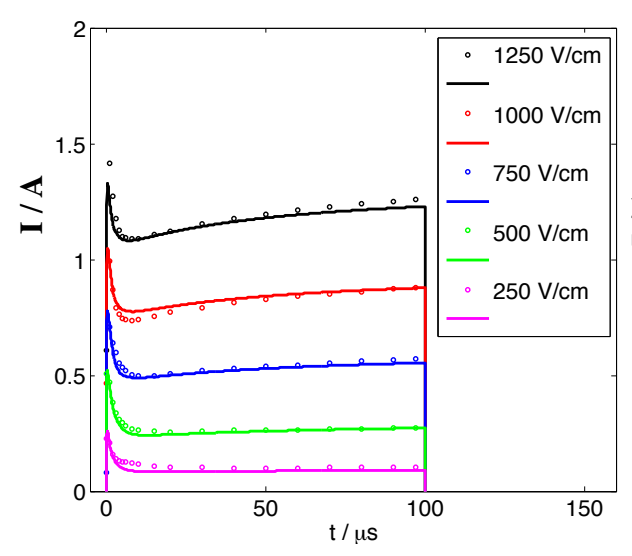

(a)

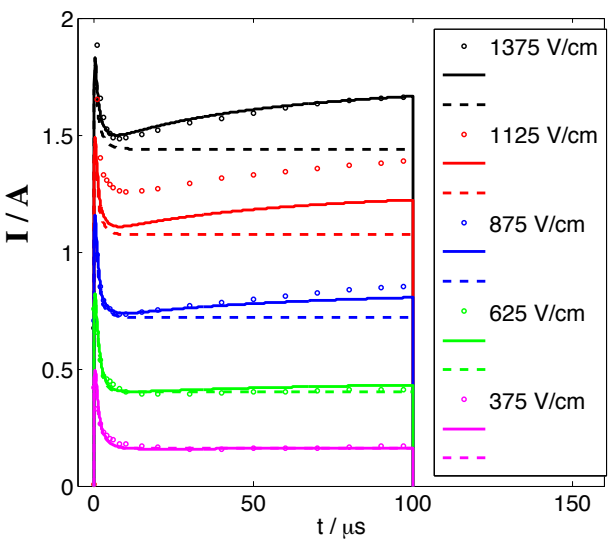

(b)

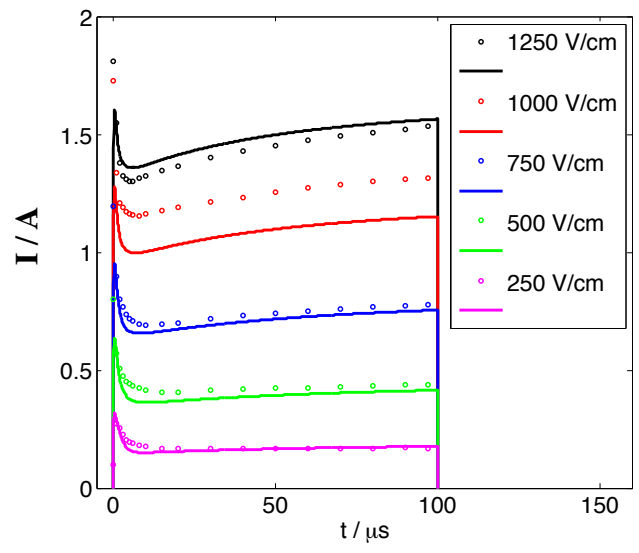

(c) 
Figure 3

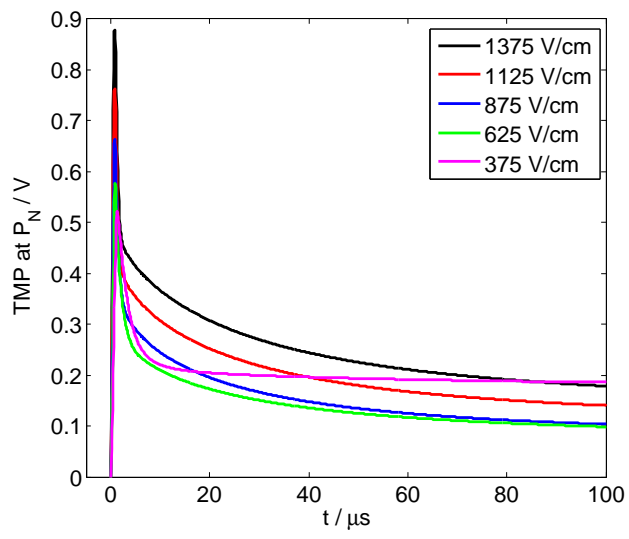

(a)

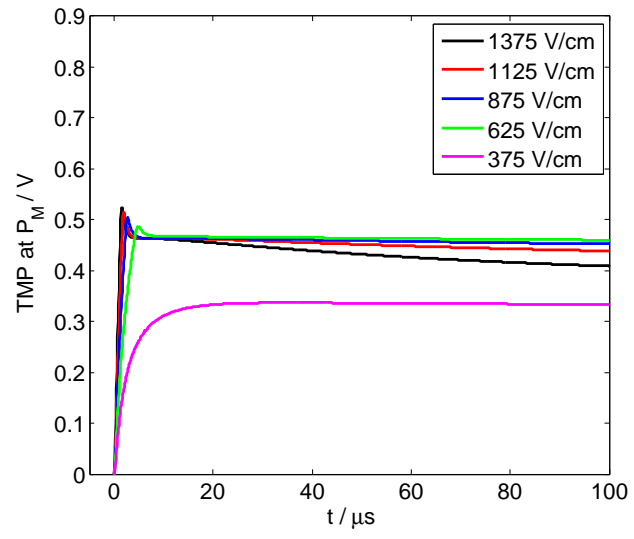

(b) 
Figure 4

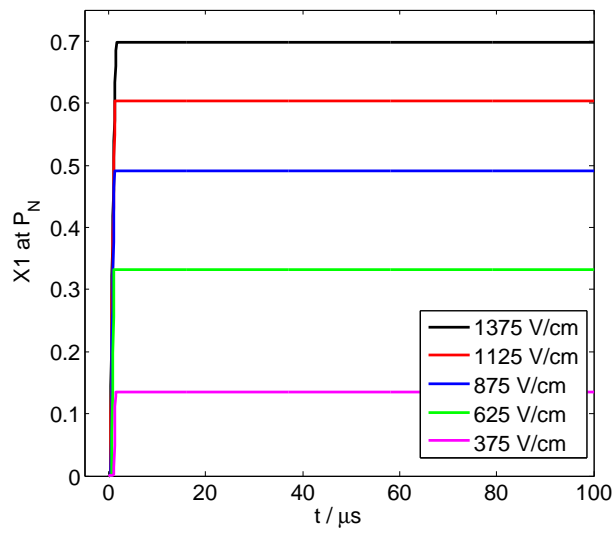

(a)

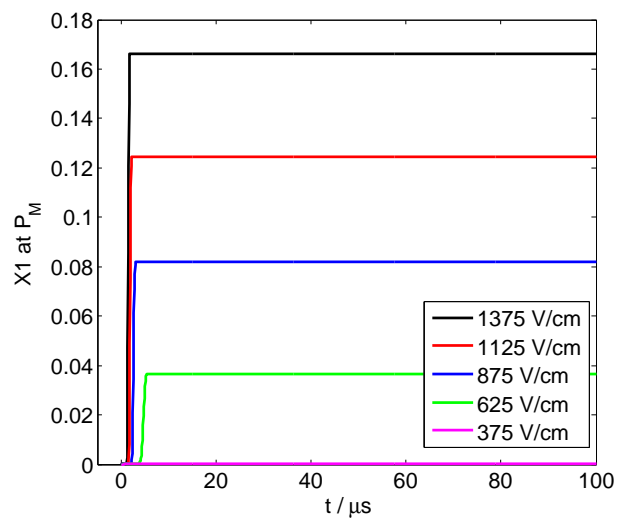

(c)

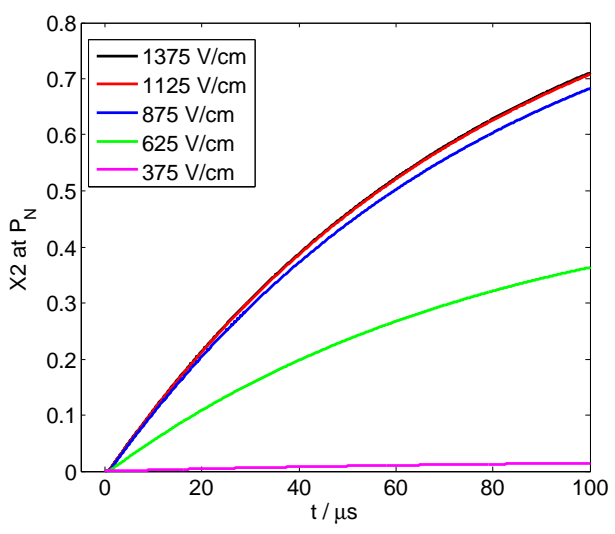

(b)

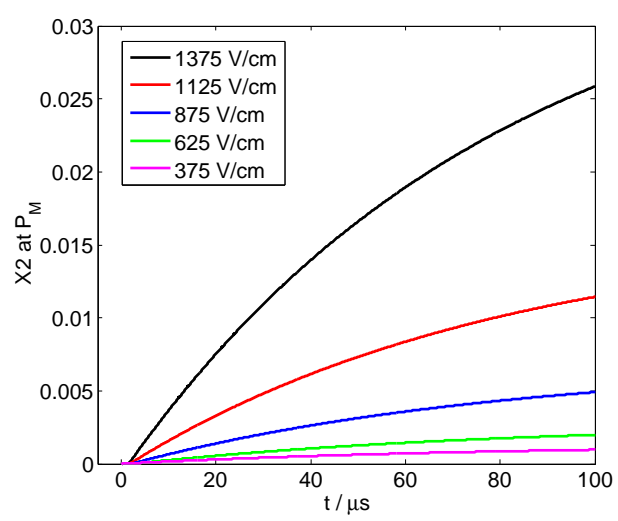

(d) 
Figure 5

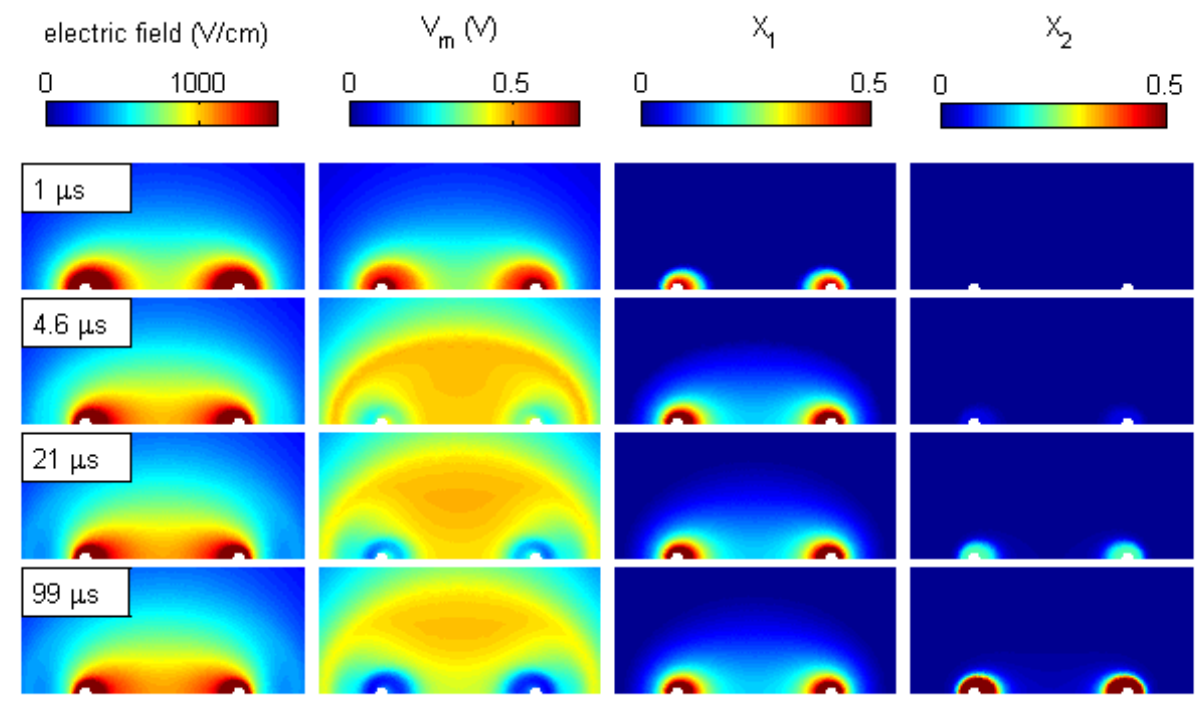


Figure 6

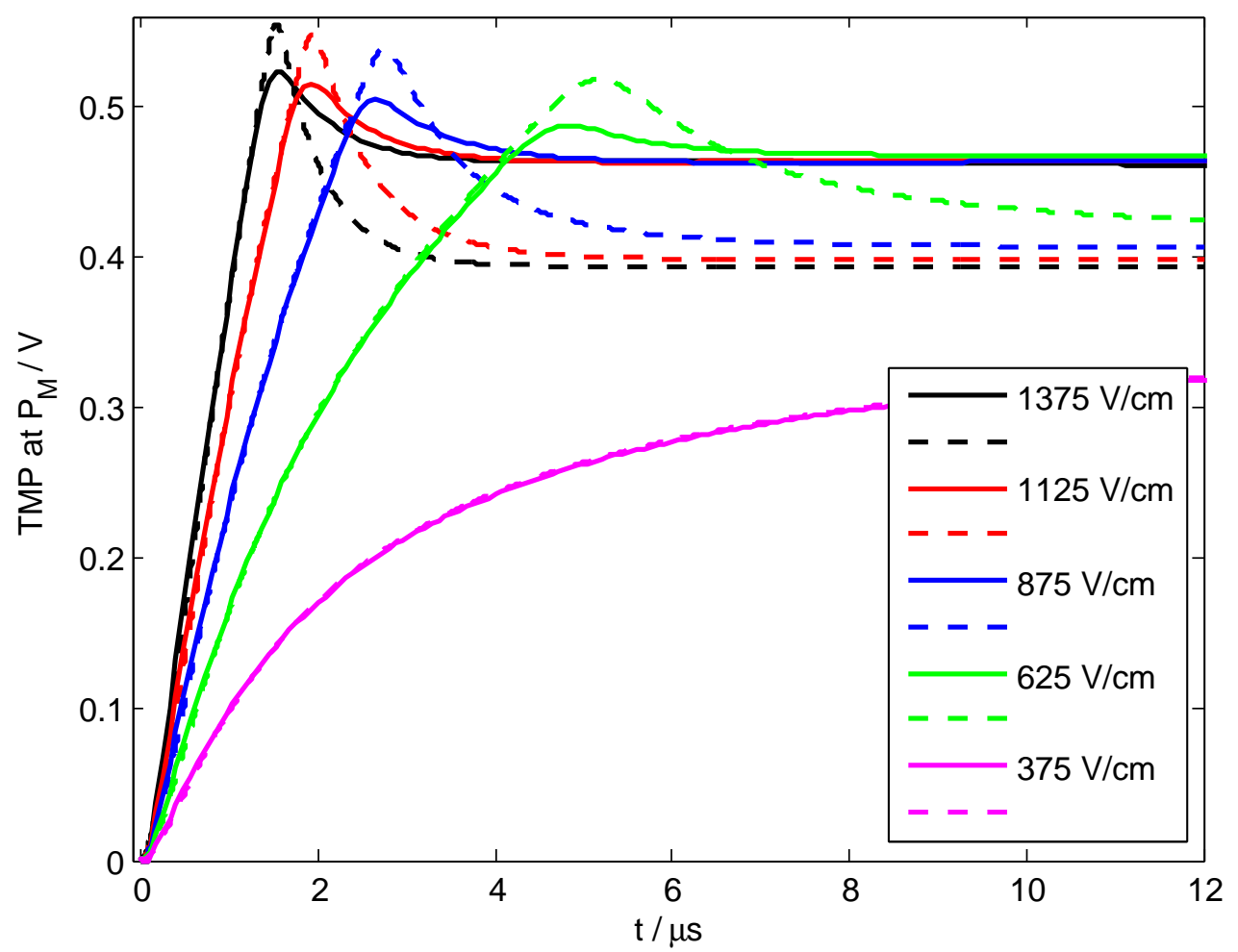


Table 1

\begin{tabular}{|c|c|c|c|c|c|}
\hline \multirow[t]{2}{*}{ Quantity } & \multirow[t]{2}{*}{ Symbol } & \multirow[t]{2}{*}{ Unit } & \multicolumn{3}{|c|}{ Diameter of the needles } \\
\hline & & & $\begin{array}{l}0.3 \mathrm{~mm} \\
\text { animal } 1\end{array}$ & $\begin{array}{c}0.7 \mathrm{~mm} \\
\text { animal } 2\end{array}$ & $\begin{array}{c}1.1 \mathrm{~mm} \\
\text { animal } 3\end{array}$ \\
\hline $\begin{array}{l}\text { Extracellular medium } \\
\text { conductivity }\end{array}$ & $\sigma_{e}$ & $S / m$ & 0.08 & 0.08 & 0.12 \\
\hline $\begin{array}{l}\text { Intracellular medium } \\
\text { conductivity }\end{array}$ & $\sigma_{c}$ & $S / m$ & 0.35 & 0.35 & 0.20 \\
\hline $\begin{array}{c}\text { Membrane } \\
\text { relative permittivity }\end{array}$ & $\epsilon_{m}$ & & 60000 & 60000 & 40000 \\
\hline $\begin{array}{l}\text { Membrane conductivity } \\
\text { before electroporation }\end{array}$ & $\sigma_{m 0}$ & $m S / m$ & 10 & 10 & 10 \\
\hline $\begin{array}{l}\text { Typical size } \\
\text { of a cell }\end{array}$ & $\mathrm{d}_{\text {cell }}$ & $\mu m$ & 22 & 22 & 22 \\
\hline $\begin{array}{l}\text { Membrane conductivity } \\
\text { for the 1rst process }\end{array}$ & $\sigma_{m 1}$ & $S / m$ & 3 & 3 & $\overline{3}$ \\
\hline $\begin{array}{c}\text { Time constant } \\
\text { for the 1rst process }\end{array}$ & $\tau_{1}$ & $\mu s$ & 1 & 1 & 1 \\
\hline $\begin{array}{c}\text { Transmembrane voltage } \\
\text { threshold }\end{array}$ & $\mathrm{V}_{t h}$ & V & 0.52 & 0.52 & 0.52 \\
\hline $\begin{array}{l}\text { Second parameter } \\
\text { in the sigmoid } \beta_{1}\end{array}$ & $k_{1}$ & $V^{-1}$ & 40 & 40 & 40 \\
\hline $\begin{array}{l}\text { Membrane conductivity } \\
\text { for the } 2 \text { nd process }\end{array}$ & $\sigma_{m 2}$ & $S / m$ & 10 & 7 & 10 \\
\hline $\begin{array}{c}\text { Time constant } \\
\text { for the } 2 \text { nd process }\end{array}$ & $\tau_{2}$ & $\mu s$ & 80 & 80 & 80 \\
\hline $\begin{array}{l}\text { First parameter } \\
\text { in the sigmoid } \beta_{2}\end{array}$ & $\mathrm{X}_{t h}$ & & 0.33 & 0.33 & 0.27 \\
\hline $\begin{array}{l}\text { Second parameter } \\
\text { in the sigmoid } \beta_{2}\end{array}$ & $k_{2}$ & & 10 & 10 & 10 \\
\hline
\end{tabular}


Table 2

\begin{tabular}{cccc}
\hline Quantity & Symbol & Unit & Value \\
\hline $\begin{array}{c}\text { Membrane conductivity } \\
\text { for the formation of pores }\end{array}$ & $\sigma_{m 1}^{\prime}$ & $S / m$ & 6.0 \\
\hline $\begin{array}{c}\text { Barrier energy within the pore } \\
\text { for the electrodiffusion term }\end{array}$ & $w_{0}$ & & 0.85 \\
\hline $\begin{array}{c}\text { Relative entrance length of pores } \\
\text { for the electrodiffusion term }\end{array}$ & $\mathrm{n}$ & & 0.15 \\
\hline $\begin{array}{c}\text { Initial density of pores } \\
\text { when } V_{m}=0 \mathrm{~V}\end{array}$ & $N_{0}$ & $\mathrm{~cm}^{-2}$ & $1.5 \times 10^{5}$ \\
\hline $\begin{array}{c}\text { Maximum density } \\
\text { of pores }\end{array}$ & $N_{\max }$ & $\mathrm{cm}^{-2}$ & $10^{10}$ \\
\hline $\begin{array}{c}\text { Characteristic voltage } \\
\text { for electroporation }\end{array}$ & $V_{e p}$ & $V^{2}$ & 0.11 \\
\hline $\begin{array}{c}\text { Parameter in the } \\
\text { function } \tau\end{array}$ & $\alpha$ & $\mathrm{cm}^{-2} s^{-1}$ & $10^{5}$ \\
\hline $\begin{array}{c}\text { Parameter in the } \\
\text { function } \beta\end{array}$ & $q$ & & 2.5 \\
\hline
\end{tabular}

